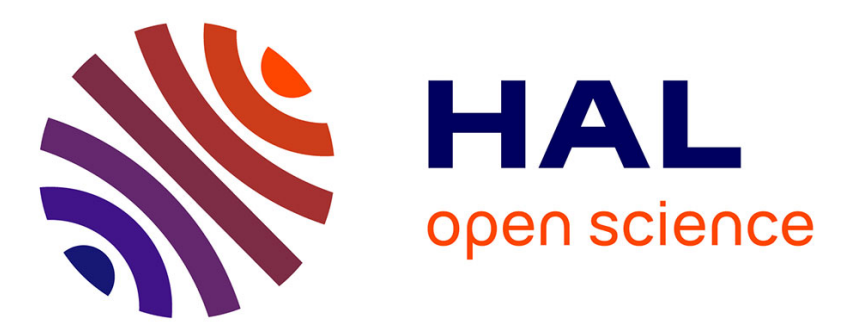

\title{
Seismic vulnerability assessment of a RC structure before and after FRP retrofitting
}

Cédric Desprez, Panagiotis Kotronis, Jacky Mazars

\section{To cite this version:}

Cédric Desprez, Panagiotis Kotronis, Jacky Mazars. Seismic vulnerability assessment of a RC structure before and after FRP retrofitting. Bulletin of Earthquake Engineering, 2015, 13 (2), pp.539-564. 10.1007/s10518-014-9621-1 . hal-03286595

\section{HAL Id: hal-03286595 \\ https://hal.science/hal-03286595}

Submitted on 28 Jul 2021

HAL is a multi-disciplinary open access archive for the deposit and dissemination of scientific research documents, whether they are published or not. The documents may come from teaching and research institutions in France or abroad, or from public or private research centers.
L'archive ouverte pluridisciplinaire HAL, est destinée au dépôt et à la diffusion de documents scientifiques de niveau recherche, publiés ou non, émanant des établissements d'enseignement et de recherche français ou étrangers, des laboratoires publics ou privés.

\section{다)(1) $(5$}

Distributed under a Creative Commons Attribution - NonCommercial| 4.0 International 


\title{
Seismic vulnerability assessment of a RC structure before and after FRP retrofitting
}

\author{
Cédric Desprez • Panagiotis Kotronis · Jacky Mazars
}

\begin{abstract}
In earthquake engineering, reliable vulnerability assessment tools suitable to existing reinforced concrete structures are necessary in order to mitigate the seismic risk. Furthermore, amongst the wide range of technical solutions available for structural upgrading, external reinforcement by fiber reinforced polymer (FRP) is often an interesting option. Nevertheless, the use of FRP is limited, one of the reasons being the lack of predictive numerical tools allowing for vulnerability assessment. Based on a case study, this article presents a simplified modeling strategy to assess the seismic vulnerability of an existing reinforced concrete building before and after FRP retrofitting. The structure is simulated using multifiber beam elements and constitutive laws based on damage mechanics and plasticity, while the dynamic characteristics of the numerical model are validated using in-situ ambient vibration records. Nonlinear transient dynamic analysis studies are performed using a synthetic earthquake signal compatible with the Eurocode 8 spectra. Local indicators are adopted to quantify the damage level in the structure before and after FRP retrofitting, in correspondence with the European Macroseismic Scale 98. One of the main conclusions of this study is that the use of local indicators can lead to contradictory assessment results with the evaluations based on global indicators as adopted in HAZUS or Risk-UE.
\end{abstract}

Keywords Structure $\cdot$ Vulnerability $\cdot$ Assessment $\cdot$ Retrofitting $\cdot$ Multifiber $\cdot$ FRP

\footnotetext{
C. Desprez $(\bowtie)$

Département Matériaux et Structures, Université Paris-Est, IFSTTAR, 14-20 boulevard Newton, 77447 Marne-la-Vallée Cedex 2, France

e-mail: cedric.desprez@ifsttar.fr
}

\section{J. Mazars}

Laboratoire Sols, Solides, Structures - Risques, Institut National Polytechnique de Grenoble, Domaine Universitaire, BP53, 38041 Grenoble Cedex 9, France

e-mail: Jacky.Mazars@inpg.fr

P. Kotronis

GeM (Institut de Recherche en Génie Civil et Mécanique), LUNAM Université/Ecole Centrale de Nantes/Université de Nantes/CNRS, 1 Rue de la Noë, 44321 Nantes, France

e-mail: Panagiotis.Kotronis@ec-nantes.fr 


\section{Introduction}

Mitigation through retrofitting of existing reinforced concrete (RC) structures is an important issue in earthquake engineering. Amongst the wide range of available technical solutions, the use of fiber reinforced polymer (FRP) is sometimes adopted. FRP can be seen as an answer to the lack of existing steel bars in RC elements. In order to facilitate the structural design procedure efficient numerical tools are however needed, able to quantify the structural vulnerability before and after retrofitting.

Due to their simplicity, structural engineers often adopt nonlinear static pushover analysis schemes. Although recent developments improved the accuracy and the applicability of the method, see for example the multimodal analysis considering the influence of several modes in the structural response (Chopra and Goel 2001, 2004), the adaptive pushover that deals with stiffness degradation (Antoniou and Pinho 2004; Kalkan and Kunnath 2006) or the work of Penelis and Kappos (2002) and Fajfar et al. (2005) introducing torsional effects, a numerical strategy based on a pushover analysis cannot be used as a general tool. It is not adequate for example for the structural assessment of $3 D$ irregular structures submitted to severe earthquake loadings or when higher order modes dominate the nonlinear structural behavior. For these cases, a nonlinear dynamic analysis is more appropriate.

The main limitations of a refined $3 D$ nonlinear dynamic analysis are the computational cost, the complexity of the finite element mesh and the huge amount of the obtained numerical results. This paper presents a simplified nonlinear dynamic analysis strategy to assess the vulnerability of an existing RC structure before and after FRP retrofitting. The numerical model is done using tri-dimensional multifiber Timoshenko beam elements (Guedes et al. 1994) and constitutive laws based on damage mechanics (La Borderie 1991; La Borderie et al. 1994) and plasticity (Menegotto and Pinto 1973). The use of beam elements leads to a reduced number of degrees of freedom and thus to acceptable computational times. The combination of multifiber beams for the structural elements (beams, columns, walls) and advanced nonlinear constitutive models for concrete and steel has been proven very efficient in recent research studies (Mazars et al. 2004; Kotronis et al. 2005; Grange et al. 2009, 2011). Comparison of experimental with the numerical results showed that this simplified modeling strategy is able to reproduce global (forces/displacements) but also local results (strains), especially when bending behavior is predominant (as for the case of the studied building).

The Grenoble City Hall in France (GCH) is chosen as case study. In order to validate the dynamic characteristics of the numerical model, results coming from the permanent monitoring of the building are used (Michel 2007, 2009). The structural assessment is performed with and without FRP retrofitting following the Eurocode 8 (EC8) prescriptions. Local quantities (damage variables and plastic strains) are adopted to quantify the damage level in the structure in accordance with the European Macroseismic Scale (EMS 98). The HAZUS (ATC-40 1996) and the Risk-UE method (RISK 2003) are finally used and the results are compared with the ones coming from the local analysis.

\section{Simplified modeling strategy}

The Grenoble City Hall (GCH) (Fig. 1) is a RC building constructed in 1966. It is composed of two distinct parts, a tower and a peripheral building. Only the tower is studied hereafter. Grenoble's area is classified as a moderate seismic zone, subject to local site effects. The seismic level is medium with a nominal acceleration between 1.6 and $3 \mathrm{~m} / \mathrm{s}^{2}$ according to the French seismic mapping (Planseisme 2011). 


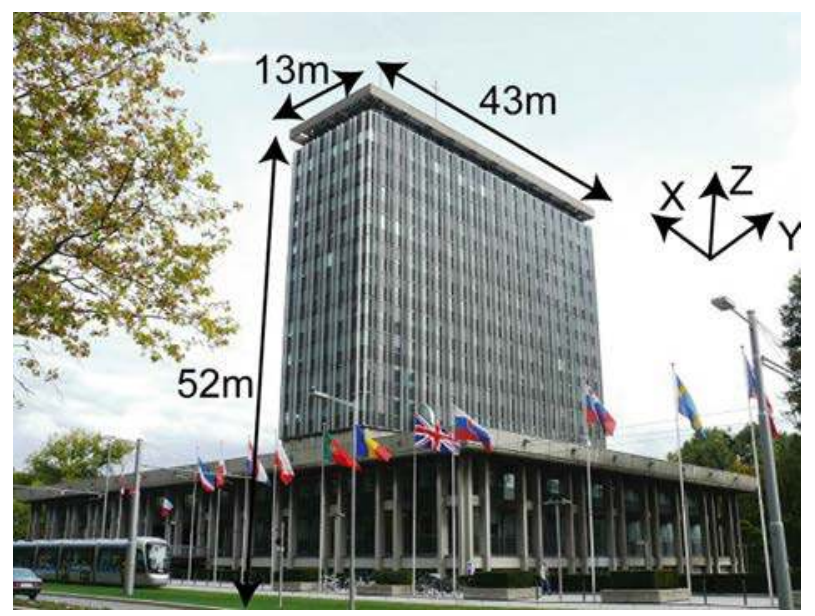

Fig. 1 CGH: view of the tower and the peripheral building

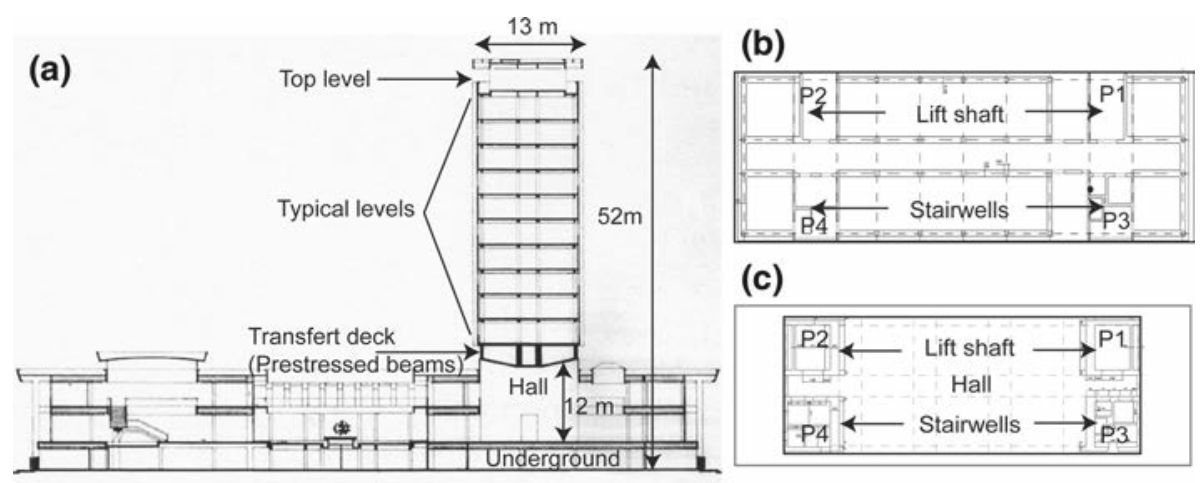

Fig. 2 GCH. a Transverse view of the structure, b structural frame of a typical level: 1st to 10th and $\mathbf{c}$ structural frame of the hall

\subsection{Geometrical and material characteristics}

The tower is $52 \mathrm{~m}$ high, $43 \mathrm{~m}$ long and $13 \mathrm{~m}$ wide (Fig. 1). The upper part is an eleven-story frame supported by a large transfer deck with pre-stressed concrete beams (Fig. 2a). The lower part of the tower is composed of a $12 \mathrm{~m}$ height hall and an underground level. The main structural frame of the tower is made of four RC piers (cores) containing the lift shafts and stairwells (Fig. 2b, c). From the basement to the deck the piers are of "Square type" and of "U type" above the deck till the top. Except from the top level (11th) which contains RC walls, all the other levels (1st to 10th) follow a beam-column frame design. The foundations of the tower are $\mathrm{RC}$ circular deep piles.

The material characteristics of the $\mathrm{GCH}$ being unknown, the adopted numerical values (Table 1) are based on the usual values corresponding to the 1960-1970 period.

\subsection{Numerical meshing}

In order to decrease the number of the necessary degrees of freedom (DOF), $3 D$ Timoshenko multifiber beam elements are used for the spatial discretization (Fig. 3) (Guedes et al. 1994; 
Table 1 Concrete and steel characteristics

\begin{tabular}{|c|c|c|c|c|}
\hline \multirow[t]{2}{*}{ Concrete } & Compression strength & Tension strength & & Young modulus \\
\hline & $30 \mathrm{MPa}$ & $3 \mathrm{MPa}$ & & $32 \mathrm{GPa}$ \\
\hline \multirow[t]{2}{*}{ Steel } & Yield limit & Young modulus & Failure & Strain at failure \\
\hline & $400 \mathrm{MPa}$ & $200 \mathrm{GPa}$ & $461 \mathrm{MPa}$ & $9 \%$ \\
\hline
\end{tabular}

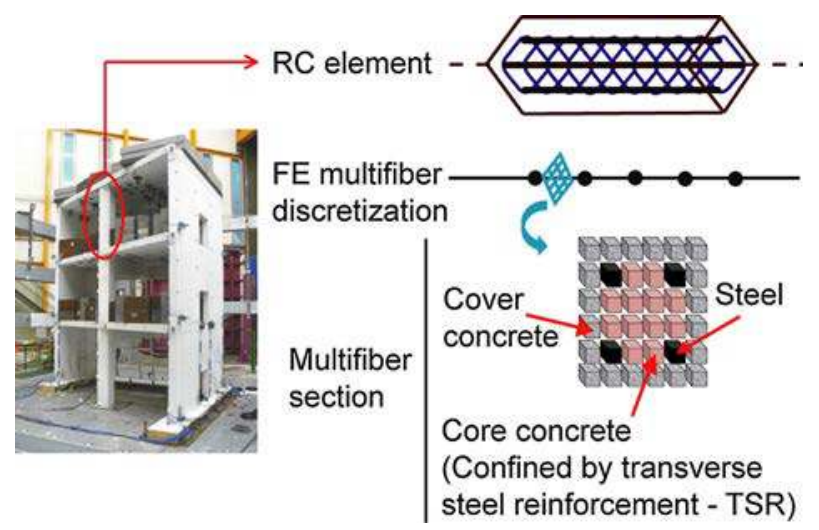

Fig. 3 Modeling strategy-multifiber beam concept

(a)

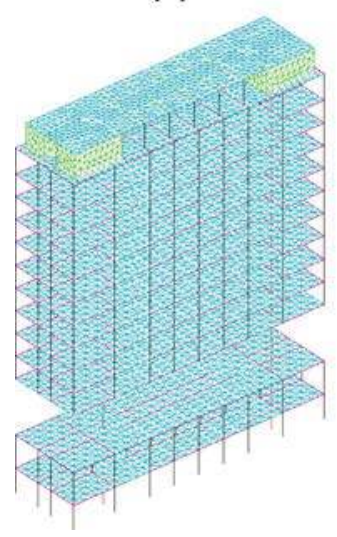

(b)

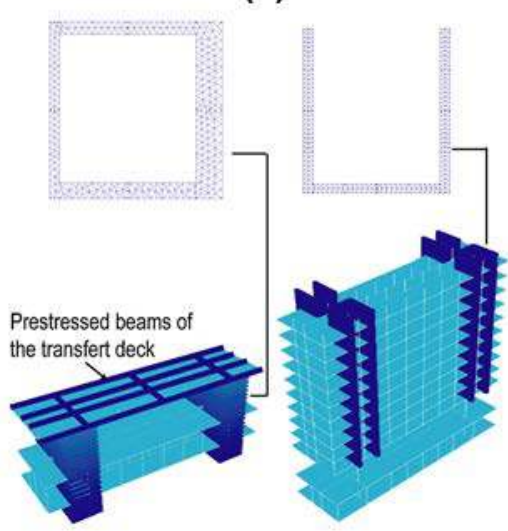

(c)

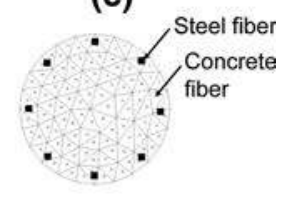

(d)

Fig. 4 GCH modeling. a Finite element mesh of the tower, $\mathbf{b}$ simplified geometry of the piers and the transfert deck, $\mathbf{c}$ multifiber section of a circular column in a typical level (diameter $\phi 45 \mathrm{~cm}$ ) and $\mathbf{d}$ top story mesh

Kotronis and Mazars 2005; Kotronis et al. 2005; Mazars et al. 2006). Computations are done with the finite element code Cast3m (Cast3m 2013; Combescure 2000).

Figure $4 \mathrm{a}$ shows the finite element mesh of the tower. Nonlinear multifiber beam elements are used for the piers, beams and columns. The slabs and the walls at the top level (11th) are discretized using linear elastic Kirchhoff plate elements. Linear beam elements are adopted for the pre-stressed transfer deck. The total number of DOF is 58848. Details about the discretization of the different parts are provided hereafter. 


\subsubsection{Piers, columns and beams}

In a typical level, all piers and columns are modeled using 5 Timoshenko multifiber beams. In the underground and the first level above the deck where a higher demand level is expected, 15 elements are used to improve accuracy. In order to decrease the necessary number of fibers, the section of the piers is simplified (Fig. 4b); openings are not precisely discretized but the total area and flexural inertia are equal to the exact ones. The sections of the beams and columns are identical to the real ones. The multifiber sections are discretized using $5-20 \mathrm{~cm}$ edge triangular elements representing the concrete fibers and square elements representing the steel fibers (Fig. 4c). Each steel fiber represents a 5 steel bars group with an area of approximately $5 \mathrm{~cm}^{2}$.

\subsubsection{Transfer deck}

Although the GCH is relatively well documented, details about the structural design of the transfer deck are unknown. The numerical model of the transfer deck is therefore based on architectural plans and consists of four longitudinal beams $(2 \mathrm{~m} \times 0.6 \mathrm{~m})$ and three transverse beams $(2 \mathrm{~m} \times 1.15 \mathrm{~m})$ (Fig. $4 \mathrm{~b})$. Due to the pre-stressed effect an elastic linear behavior is assumed.

\subsubsection{Top story}

Considering the specific design of this story that contains RC walls and presents a higher stiffness, linear elastic Kirchhoff plate elements are introduced in the numerical model (Fig. 4d).

\subsubsection{Boundary conditions}

Due to the existence of pile foundations, the numerical model is assumed fixed at the base. Ambient vibrations measurements provided a verification of this assumption for small dynamic loadings (Michel et al. 2009).

\subsection{Constitutive laws}

A constitutive model suitable for cyclic loadings is associated at each fiber of the multifiber elements. The La Borderie damage mechanics law is used for concrete (La Borderie 1991; La Borderie et al. 1994) and the Menegotto \& Pinto plasticity model for steel (Menegotto and Pinto 1973). The concrete model takes into account the opening and closing of cracks while the steel model is able to consider the buckling of the reinforced bars. Shear is considered linear. A short description of the La Borderie and Menegotto-Pinto models is presented hereafter.

\subsubsection{La Borderie's constitutive model}

This concrete model is based on damage mechanics and takes into account the crack opening and closing (Fig. 5) during cyclic loading. The model's general formulation is tridimensional $(3 D)$, but only the uniaxial $(1 D)$ version is used herein, according to the multifiber modeling needs. An overview of the adopted parameters is presented in Table 2. The total 


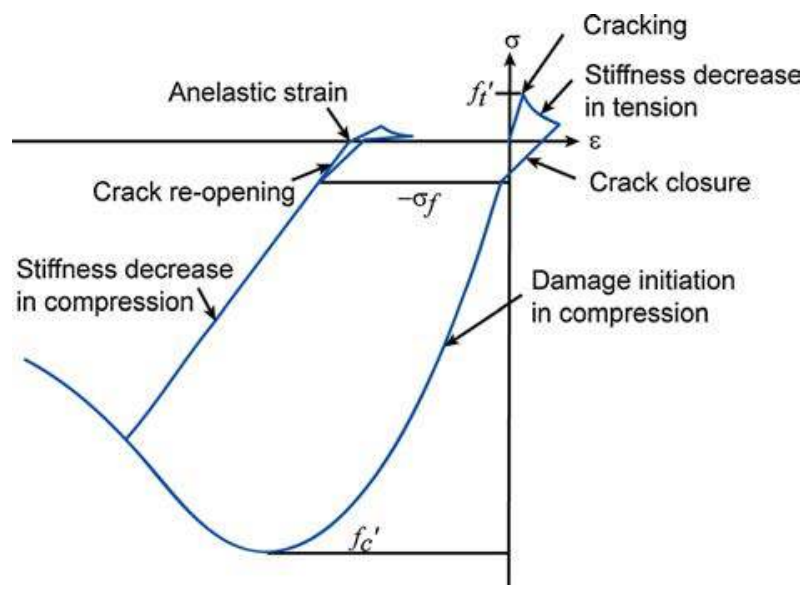

Fig. 5 La Borderie model-Uniaxial stress-strain relation

Table 2 Concrete model parameters

\begin{tabular}{lll}
\hline Parameters & Tension & Compression \\
\hline Young's modulus (GPa) & $E_{b}=32$ & \\
Poisson ratio & $\nu_{b}=0.2$ & \\
Crack closure stress (MPa) & $\sigma_{f}=-3$ & \\
Energetic threshold (MPa) & $Y 01=2.7 \times 10^{-4}$ & $Y 02=2.5 \times 10^{-2}$ \\
Material coefficients & $A 1=3 \times 10^{-3}$ & $A 2=7 \times 10^{-6}$ \\
& $B 1=1.0$ & $B 2=1.45$ \\
Anelastic strain parameters (MPa) & $\beta 1=1.075$ & $\beta 2=-40$ \\
Volumetric mass $\left(\mathrm{Kg} / \mathrm{m}^{3}\right)$ & $\rho_{b}=2,400$ & \\
\hline
\end{tabular}

strain $(\varepsilon)$ is defined as the sum of an elastic $\left(\varepsilon_{e}\right)$ and an anelastic part $\left(\varepsilon_{a}\right)$ (Eqs. 1, 2, and 3).

$$
\begin{aligned}
\varepsilon & =\varepsilon_{e}+\varepsilon_{a} \\
\varepsilon_{e} & =\frac{\sigma^{+}}{E\left(1-D_{1}\right)}+\frac{\sigma^{-}}{E\left(1-D_{2}\right)} \\
\varepsilon_{a} & =\frac{\beta_{1} \cdot D_{1}}{E\left(1-D_{1}\right)} F^{\prime}(\sigma)+\frac{\beta_{2} \cdot D_{2}}{E\left(1-D_{2}\right)}
\end{aligned}
$$

$\sigma^{+}$and $\sigma^{-}$are, respectively, the tensile and compressive stresses (Eqs. 4 and 5); $E$ is the Young's modulus; and $\beta_{1}$ and $\beta_{2}$ are material constant parameters controlling the anelastic strains in tension and compression, respectively;

$$
\begin{aligned}
& \text { if } \sigma>0 \text { then } \sigma^{+}=\sigma \text { and } \sigma^{-}=0 \\
& \text { if } \sigma<0 \text { then } \sigma^{+}=0 \text { and } \sigma^{-}=\sigma
\end{aligned}
$$

$F^{\prime}(\sigma)$ is a function that controls crack opening and closing (Eq. 6); $-\sigma_{f}$ is the stress crack closure value (Fig. 5).

$$
F^{\prime}(\sigma)=\frac{d F}{d \sigma}
$$




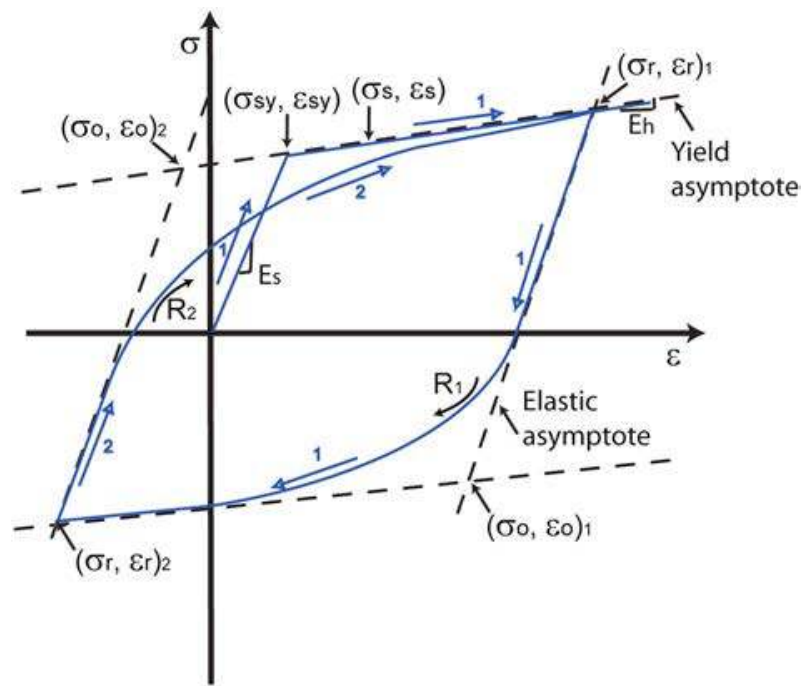

Fig. 6 Menegotto \& Pinto model-Uniaxial stress-strain relation

$$
\begin{aligned}
& \text { if } \sigma \geq 0 \text { then } F(\sigma)=\sigma \Rightarrow F^{\prime}(\sigma)=1 \\
& \text { if }-\sigma_{f} \leq \sigma<0 \text { then } F(\sigma)=\sigma\left(1+\frac{\sigma}{2 \sigma_{f}}\right) \Rightarrow F^{\prime}(\sigma)=1+\frac{\sigma}{\sigma_{f}} \\
& \text { if } \sigma \leq-\sigma_{f} \text { then } F(\sigma)=\frac{-\sigma_{f}}{2} \Rightarrow F^{\prime}(\sigma)=0
\end{aligned}
$$

$D_{1}$ and $D_{2}$ (Eq. 7) are the damage variables due to tension and compression respectively, varying from 0 (no damage) to 1 (completely damaged material). $D_{i}$ is driven by $Y_{i}$ (Eqs. 8 and 9). $Y_{0 i}$ is the initial damage threshold and $A_{i}$ and $B_{i}$ are constants directly identified from uniaxial tension and compression tests.

$$
\begin{aligned}
D_{i} & =1-\frac{1}{1+\left[A_{i}\left(Y_{i}-Y_{o i}\right)\right]^{B_{i}}} \text { with } i=1 \text { (tension) or } i=2 \text { (compression) } \\
Y_{1} & =\frac{\left(\sigma^{+}\right)^{2}}{2 E\left(1-D_{1}\right)^{2}}+\frac{\beta_{1} \cdot F(\sigma)}{E\left(1-D_{1}\right)^{2}} \\
Y_{2} & =\frac{\left(\sigma^{-}\right)^{2}}{2 E\left(1-D_{2}\right)^{2}}+\frac{\beta_{2} \cdot \sigma}{E\left(1-D_{2}\right)^{2}}
\end{aligned}
$$

\subsubsection{Menegotto-Pinto constitutive model}

The cyclic behavior of the steel bars is simulated using the classical Menegotto-Pinto model with cinematic hardening (Fig. 6) and possibility to take into account buckling by introducing a negative modulus slope in compression depending on the transverse steel reinforcement spacing. The monotonic behavior is defined through the initial Young's modulus $\left(E_{s}\right)$, the plastic threshold $\left(\varepsilon_{s y}, \sigma_{s y}\right)$, the ultimate strength and strain $\left(\varepsilon_{u}, \sigma_{u}\right)$ and the yielding slope $\left(E_{h}\right)$. The unloading and reloading process, is guided by analytic relations (Eqs. 10-13) corresponding to a set of curves ranging between the elastic and the yielding asymptotes. An overview of the adopted parameters is presented in Table 3. 
Table 3 Steel model parameters

\begin{tabular}{|c|c|c|}
\hline Parameters & Tension & Compression \\
\hline Young's modulus (GPa) & \multicolumn{2}{|l|}{$E_{a}=200$} \\
\hline Poisson ratio & \multicolumn{2}{|l|}{$v_{s}=0.3$} \\
\hline Elastic limits & \multicolumn{2}{|c|}{$\sigma_{s y}=400 \mathrm{MPa}, \varepsilon_{s y}=0.002$} \\
\hline Yielding threshold & \multicolumn{2}{|c|}{$\varepsilon_{s h}=0.03$} \\
\hline Ultimate limits & $\varepsilon_{s u}=0.09$ & $\sigma_{s u}=461 \mathrm{MPa}$ \\
\hline Material coefficients & $\begin{array}{l}A 1_{f a}=18.5 \\
A_{f a c}=0.006 \\
\rho_{f a c}=20\end{array}$ & $\begin{array}{l}A 2_{f a}=0.15 \\
A 6_{f a c}=620\end{array}$ \\
\hline Stiffness ratios between cyclic yielding and elastic regime & $B_{f a c}=0.00357$ & $C_{f a c}=0.5$ \\
\hline $\begin{array}{l}\text { Ratio between transverse steel reinforcement (TSR) spac- } \\
\text { ing and steel bar diameter }\end{array}$ & \multicolumn{2}{|l|}{$f_{\text {ald }}=5$} \\
\hline Volumetric mass $\left(\mathrm{Kg} / \mathrm{m}^{3}\right)$ & \multicolumn{2}{|l|}{$\rho_{s}=7,800$} \\
\hline
\end{tabular}

$$
\begin{aligned}
\sigma^{*} & =b \varepsilon^{*}+\left[\frac{1-b}{\left(1+\left(\varepsilon^{*}\right)^{R}\right)^{1 / R}}\right] \varepsilon^{*} \\
\sigma^{*} & =\frac{\sigma_{s}-\sigma_{r}}{\sigma_{o}+\sigma_{r}} \\
\varepsilon^{*} & =\frac{\varepsilon_{s}-\varepsilon_{r}}{\varepsilon_{o}+\varepsilon_{r}} \\
R & =R_{o}-\frac{A_{i} \xi}{A_{j}+\xi} \text { Tension }: i=1 \text { and } j=2 ; \text { Compression }: i=3 \text { and } j=4
\end{aligned}
$$

$\left(\sigma_{s}, \varepsilon_{s}\right)$ is the studied point; $\left(\sigma_{o}, \varepsilon_{o}\right)$ is the crossing point of the elastic and yielding slopes; $\left(\sigma_{r}, \varepsilon_{r}\right)$ are the coordinates of the previous point of load reversion; b is the $E_{h} / E_{s}$ ratio; $\mathrm{R}$ is a shape parameter; $\zeta$ is the ratio between the maximum reached strain during loading; $\varepsilon_{o}, R_{o}, A_{i}$ and $A_{j}$ are material constants that can be obtained from experimental results. A detailed description of the model is presented in (Menegotto and Pinto 1973).

\subsection{Numerical model validation}

The structure's ambient vibrations due to wind, road traffic or small seismic ground motions, are monitored using a permanent accelerometers network. Six tri-directional accelerometric stations are used inside the building and one outside. The response of the structure in terms of accelerations, velocities and displacements is known and thus its main natural frequencies and stiffness evolution (Michel 2007; Michel et al. 2009).

In order to validate the finite element model, a modal analysis is performed and the numerical natural frequencies are compared to the ones coming from the ambient measurements. It is found that up to the fifth frequency the numerical model reproduces correctly the insitu measurements (Fig. 7) (Michel et al. 2009). A low motion earthquake record (Fig. 8) is also used to compare the response of the numerical model with the in-situ ambient vibration records. The signal is tri-directional with a maximal peak ground acceleration of $0.023 \mathrm{~m} / \mathrm{s}^{2}$ in the horizontal direction. Comparisons of the maximum inter-story drifts (Fig. 9a) and the Fourier transforms of the top displacement signals (Fig. 9b) show again a good correlation (Michel et al. 2009). 


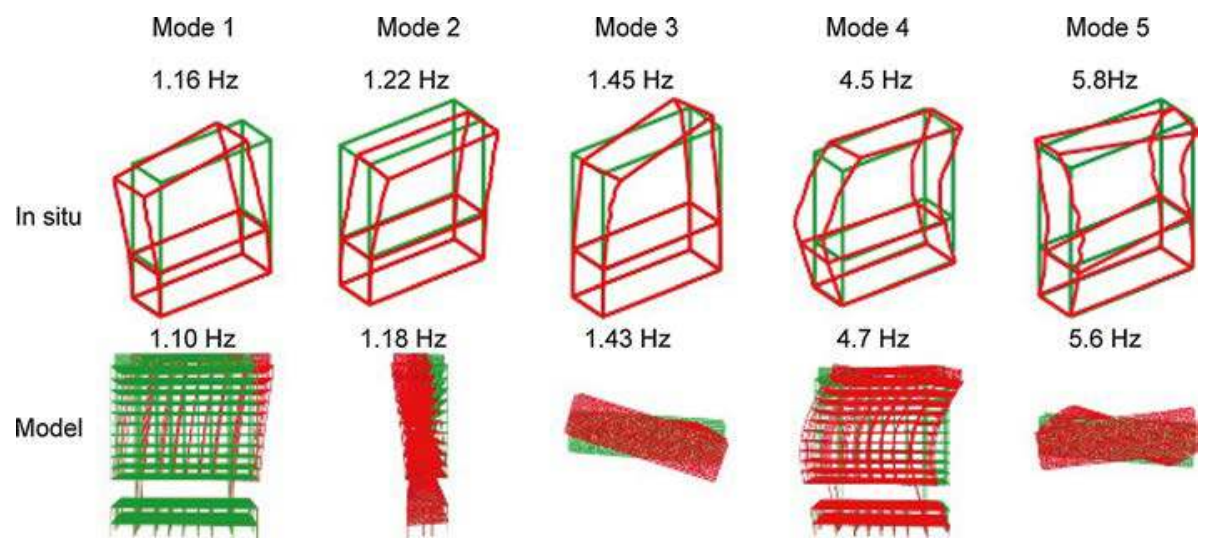

Fig. 7 GCH modeling-modal analysis; in-situ versus model

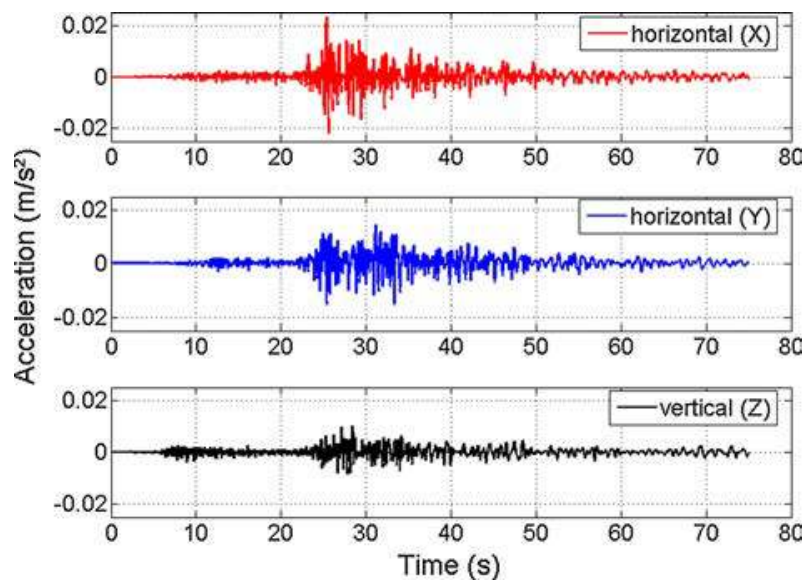

Fig. 8 In-situ record of a low seismic signal; Valorcine earthquake (Grenoble area), 2005

\section{Vulnerability assessment before FRP retrofitting}

\subsection{Synthetic EC8 earthquake}

Based on the characteristics of the GCH and the Grenoble area (Table 4), a synthetic accelerogram is created (Fig. 10a) using empiric green functions (Causse et al. 2008). This signal is tri-directional (uncoupled) and fits the EC8 design spectra (Fig. 10b). The maximum peak ground acceleration is approximately equal to $3 \mathrm{~m} / \mathrm{s}^{2}$ in the two horizontal directions and $2 \mathrm{~m} / \mathrm{s}^{2}$ in the vertical direction.

\subsection{Nonlinear dynamic analysis}

The response of the structure under the synthetic tri-directional EC8 earthquake is studied hereafter in terms of global (displacement, drift) and local (damage, strain) quantities. 

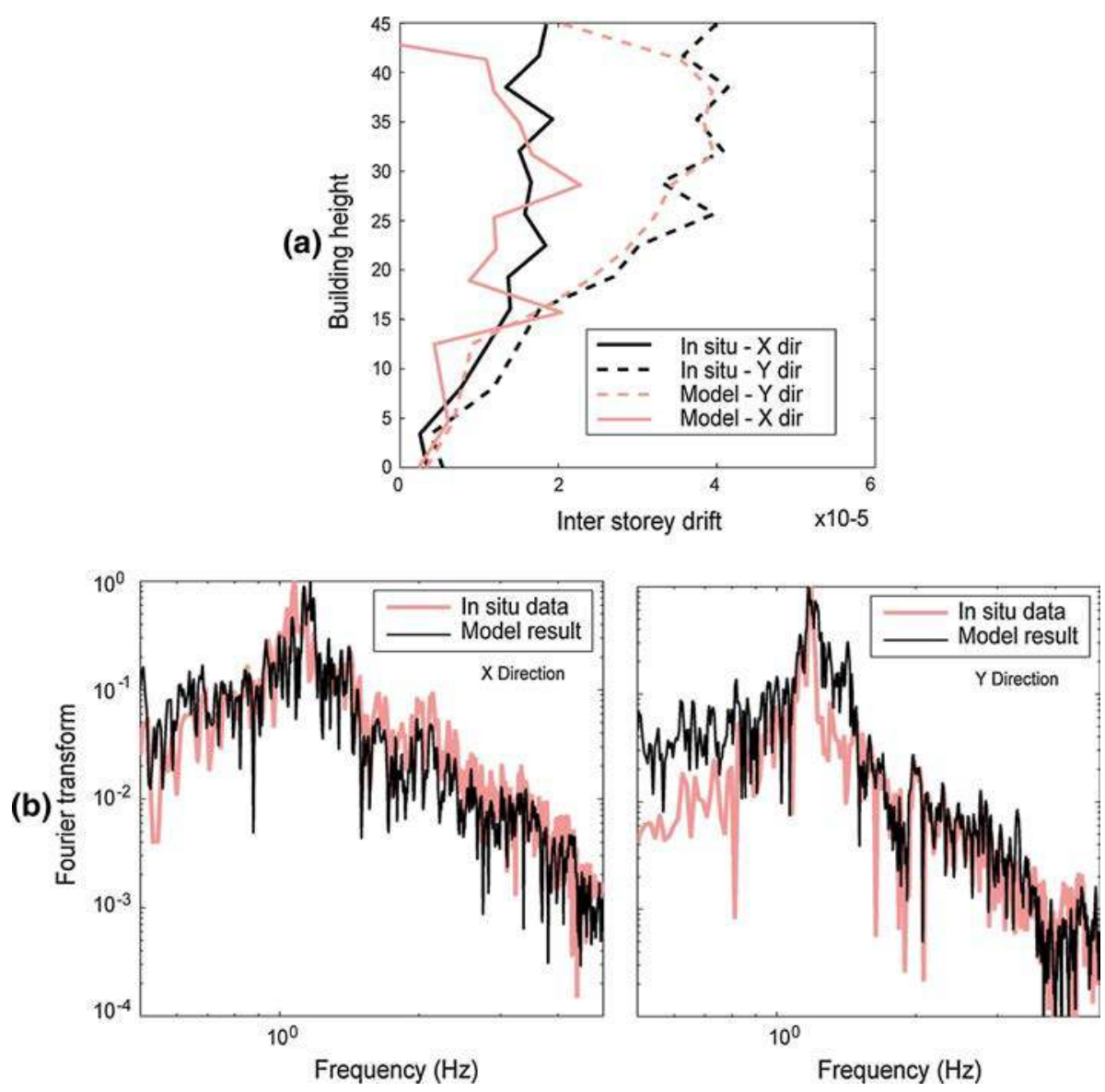

Fig. 9 CGH response to the low motion signal. a Maximum value of the inter-story drift; in-situ versus model and $\mathbf{b}$ Fourier transform of the top displacement signal; in-situ versus model

Table 4 GCH-parameters for the generation of the synthetic EC8 earthquake

\begin{tabular}{ll}
\hline Area seismic level & Medium \\
Building class & $I V$ \\
Soil class & $C$ \\
\hline
\end{tabular}

\subsubsection{Flexural behavior}

The maximum horizontal top displacements are found equal to $132.3 \times 10^{-3}$ and $127 \times 10^{-3} \mathrm{~m}$ respectively in the longitudinal $(\mathrm{X})$ and transverse $(\mathrm{Y})$ directions (Fig. 11). The vertical displacement in the center of the top slab doesn't exceed $1 \mathrm{~cm}$, a relative small value for a building of $28.7 \mathrm{~m}$ long, leading to small strain values. This last result comforts the choice of a linear elastic constitutive law for the slabs.

Stiffness is visibly higher in the lower part of the tower (rectangular piers) (Fig. 12a), something that is certainly due to the change of the piers' section (Fig. 2). The flexural behavior of the structure is obvious looking at the maximum inter-story drift diagram (Fig. 12b). Drifts 
(a)

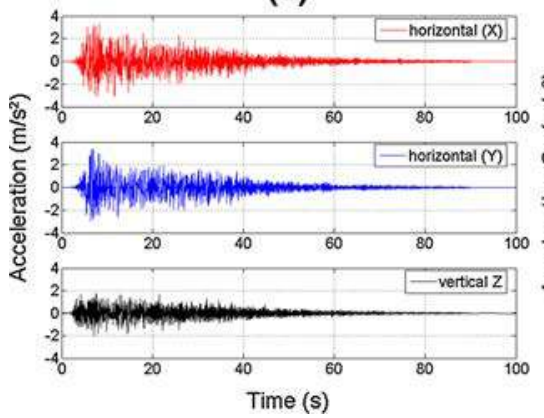

(b)

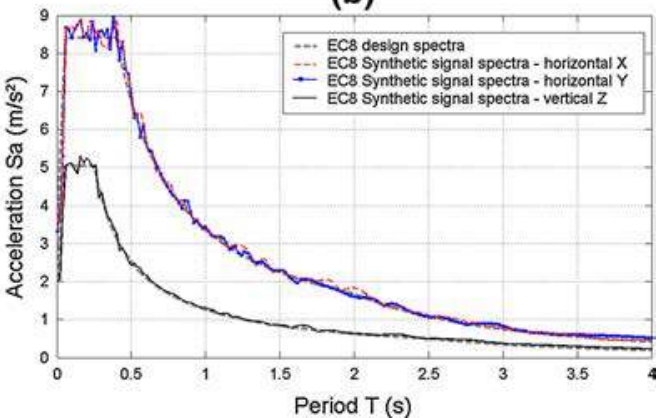

Fig. 10 Synthetic EC8 earthquake. a Tri-directional signal and b signal spectra versus EC8 design spectra

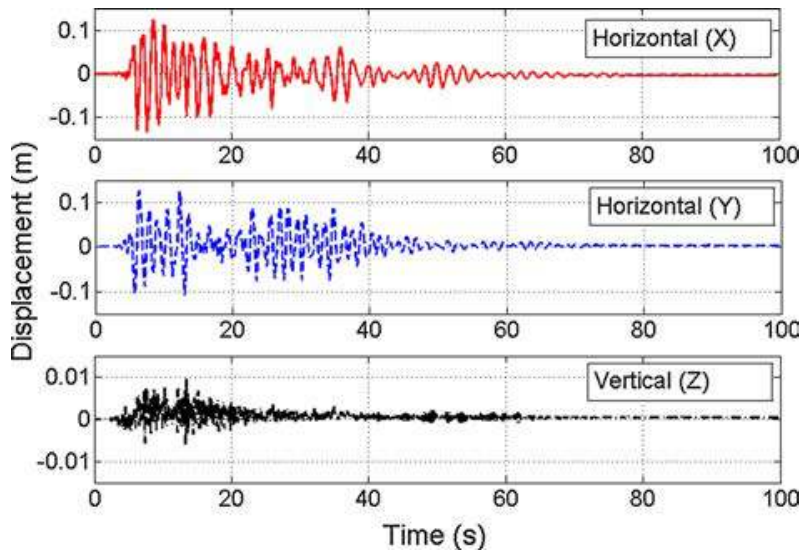

Fig. 11 CGH response to the synthetic EC8 earthquake-Displacements history at the top of the structure
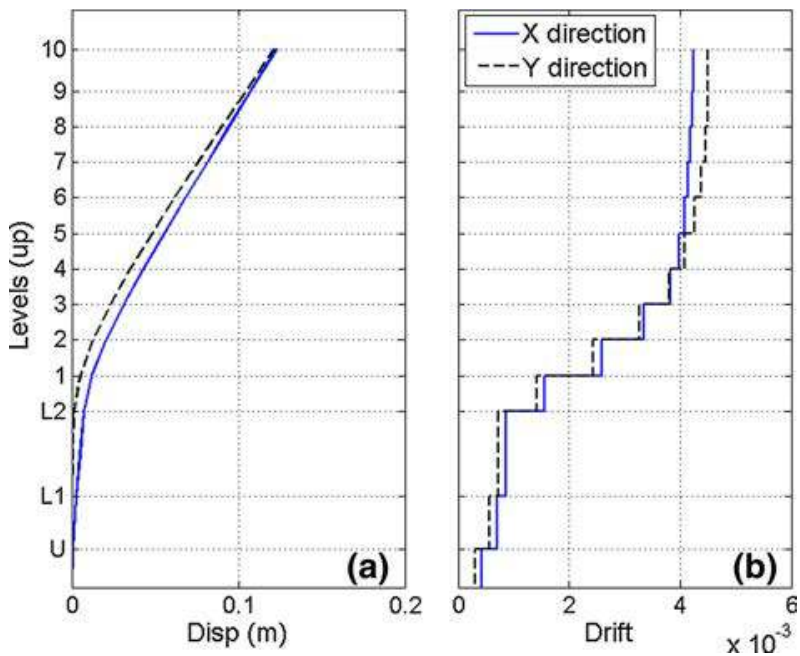

Fig. 12 CGH response to the synthetic EC8 earthquake-maximum values in pier P4: a displacements, b inter-story drifts 


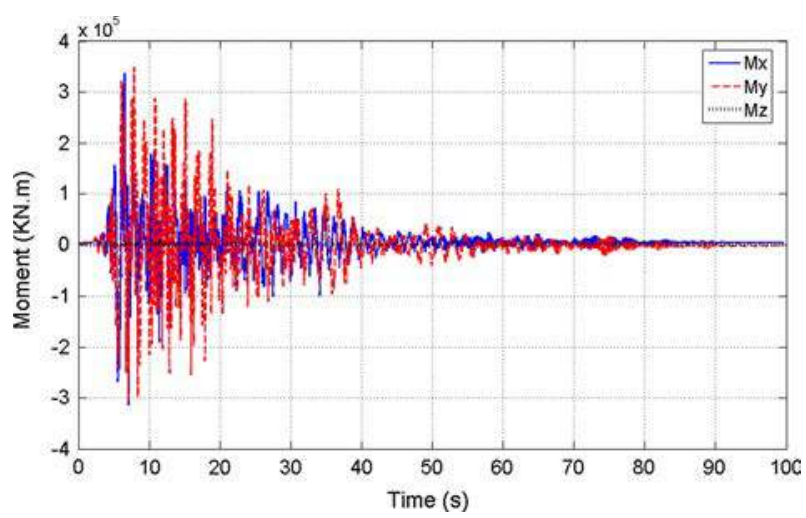

Fig. $13 \mathrm{CGH}$ response to the synthetic EC8 earthquake-time history of the bending (Mx, My) and torsion $(\mathrm{Mz})$ moments at the base of the structure-Pier P1

are higher in the upper part of the building, characteristic of a flexural behavior without important shear effects; the low values at the top floor are due to its specific design (RC walls). The maximum shear stress is found equal to $1.36 \mathrm{MPa}$ at the base of the "U-type" piers, a value lower than the Eurocode 2 prescriptions limits. The use of Timoshenko multifiber beam elements with a linear shear assumption seems thus adequate.

The structure bends mainly according to the first and second flexural modes, (60 and $30 \%$ of the effective modal mass respectively). The inflexion point is situated just above the transfer deck.

\subsubsection{Torsion effects}

Despite the $3 D$ loading and the small dissymmetry of the building (differences between the stairwell and the lift shaft cores) no significant torsional effect is observed. Moreover, as shown in Fig. 13 the torsion moment at the base of the piers is very small in comparison with the two bending moments.

\subsubsection{Damage distribution in concrete}

The two damage variables $D_{1}$ and $D_{2}$ of the concrete constitutive model are directly used as indicators of damage due to traction and compression respectively. The two variables vary between 0 (no damage) and 1 (totally damaged material).

Although damage due to traction is not representative of the building capacity, as it appears for low levels of loading and evolves fast, it gives an idea of the areas of the structure where the seismic energy is dissipated. The distribution of the $D_{1}$ variable at the final step of the calculation is represented in Fig. 14a. Tensile macro-cracks $\left(D_{1}>0.9\right)$ are localized at the base of the piers and at the first four levels above the deck. Its history evolution indicates that energy is dissipated mainly during the first $10 \mathrm{~s}$ of the signal.

High values of the compression damage variable $D_{2}\left(D_{2}>0.9\right)$ are representative of concrete crushing, spalling and possible reinforcement bucking. The distribution of the $D_{2}$ variable at the final step is found small, with a maximum value limited at $D_{2}=0.25$ and is located at the base of the "U-type" pier. Compression damage is thus not significant for the chosen earthquake signal. 
(a)

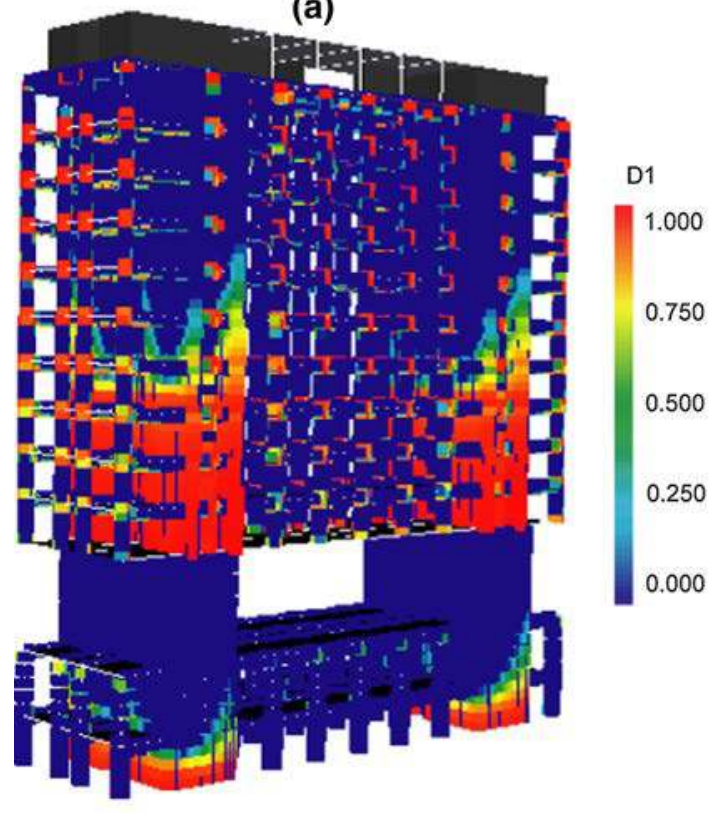

(b)

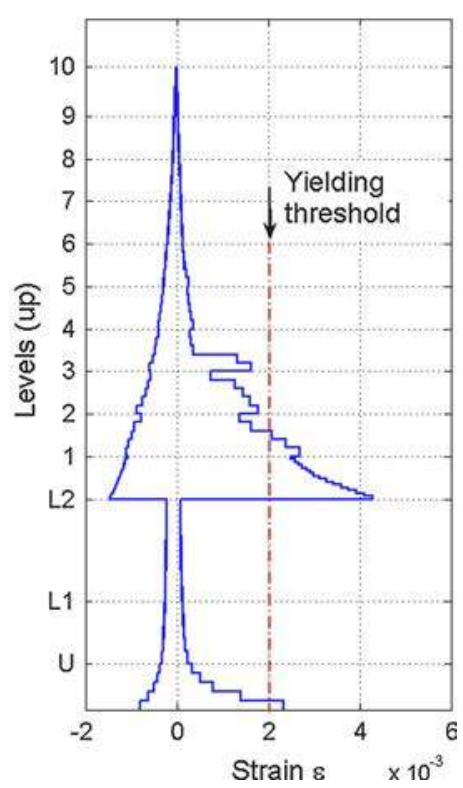

Fig. 14 CGH response to the synthetic EC8 earthquake. a Distribution of $D_{1}$ (tension damage), final step and $\mathbf{b}$ Envelop of strains in the steel bars of the pier P4; yielding threshold at $0.2 \%$

\subsubsection{Strains in steel bars}

Figure 14b shows the strains envelop in the steel bars of the pier P4. Two yielding zones are apparent: the first is located at the base of the rectangular pier. The reached value is small, but is situated in a critical area for the stability of the building. The maximum strain value $\left(4.3 \times 10^{-3}\right)$ is reached in the first level above the deck. Even if these yielding values are not excessive, it is important to take into account that the building, constructed at the $60 \mathrm{~s}$, does not comply with the capacity design philosophy.

\subsection{Damage level assessment: initial RC structure}

HAZUS (ATC-40 1996) and Risk-UE LM2 (RISK 2003) compute damage level from global indicators, as the inter-story drift or the top displacement, depending of the building typology (ie: materials, geometry...). Although these methods are widely used, they are not well adapted for the specific building where the dynamic behavior is modified (with the FRPstrengthening) without significant changes in the building geometry. In this study, the chosen modeling strategy allows obtaining global but also local indicators as damage in concrete and yielding of the steel bars. For this reason, the adopted assessment methodology in the following is based on equivalence between the European Macro-seismic Scale classification (EMS 1998) and the local variables according to the work of Lang (Lang 2002), (Table 5; Fig. 15). The results of the HAZUS (ATC-40 1996) and the Risk-UE methods (RISK 2003) are also presented in the last section of the article in order to highlight the contradictions that can be found using global and/or local variables.

According to the results of the nonlinear dynamic analysis, concrete cracking appears at the underground level and at the four first levels above the deck. Reinforcement bars yield 
Table 5 Equivalence between EMS98 and local variables (Lang 2002)

\begin{tabular}{ll}
\hline EMS 98 damage level & Identification \\
\hline $\begin{array}{l}\text { 1-Negligible to slight damage (no structural damage, } \\
\text { slight non-structural damage) }\end{array}$ & Point of onset of cracking \\
$\begin{array}{l}\text { Fine cracks in plaster over frame members or in walls at } \\
\text { the base }\end{array}$ & $\begin{array}{l}\text { Tensile stress at the extreme tensile } \\
\text { fiber of the wall section reaches the } \\
\text { tensile strength of concrete }\end{array}$ \\
$\begin{array}{l}\text { Fine cracks in partitions and infills } \\
\text { 2-Moderate damage (slight structural damage, moder- }\end{array}$ & $\begin{array}{l}\text { Behavior of the building becomes } \\
\text { nonlinear. The stiffness of the build- } \\
\text { Cracks in columns and beams of frames and in structural } \\
\text { walls }\end{array}$ \\
ing starts to reduce \\
Yield of the first wall
\end{tabular}

Cracks in partition and infill walls: fall of brittle cladding and plaster. Falling mortar from the joints of wall panels

3-Substantial to heavy damage (moderate structural damage, heavy non-structural damage)

Cracks in columns and beam column joints of frames at the base and at joints of coupled wall. Spalling of concrete cover, buckling of reinforced rods

Large cracks in partition and infill walls, failure of individual infill panels

4-Very heavy damage (heavy structural damage, very heavy non-structural damage)

Large cracks in structural elements with compression failure of concrete and fracture of re-bars; bond failure of beams reinforced bars; tilting of columns

Collapse of a few columns or of a single upper floor

5-Destruction (very heavy structural damage)

Collapse of ground floor or parts (e.g wings) of buildings

Increase nonlinear behavior of the building. The stiffness of the building tends to zero

Yield of the first wall

Ultimate displacement of the first wall, determined either by compression failure on concrete or rupture of reinforcing bars

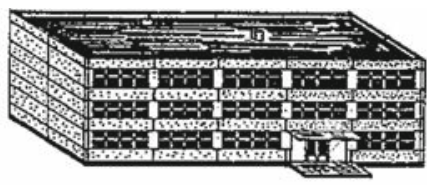

Level 1

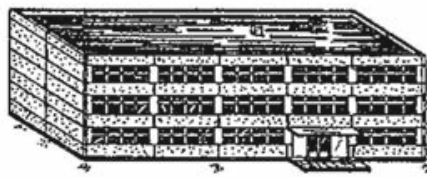

Level 2

Drop of the base shear of the building below $2 / 3$ of the maximum value

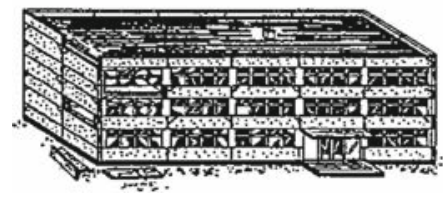

Level 3

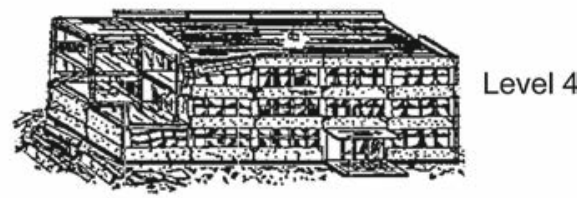

Fig. 15 EMS 98 damage level (EMS 1998) 


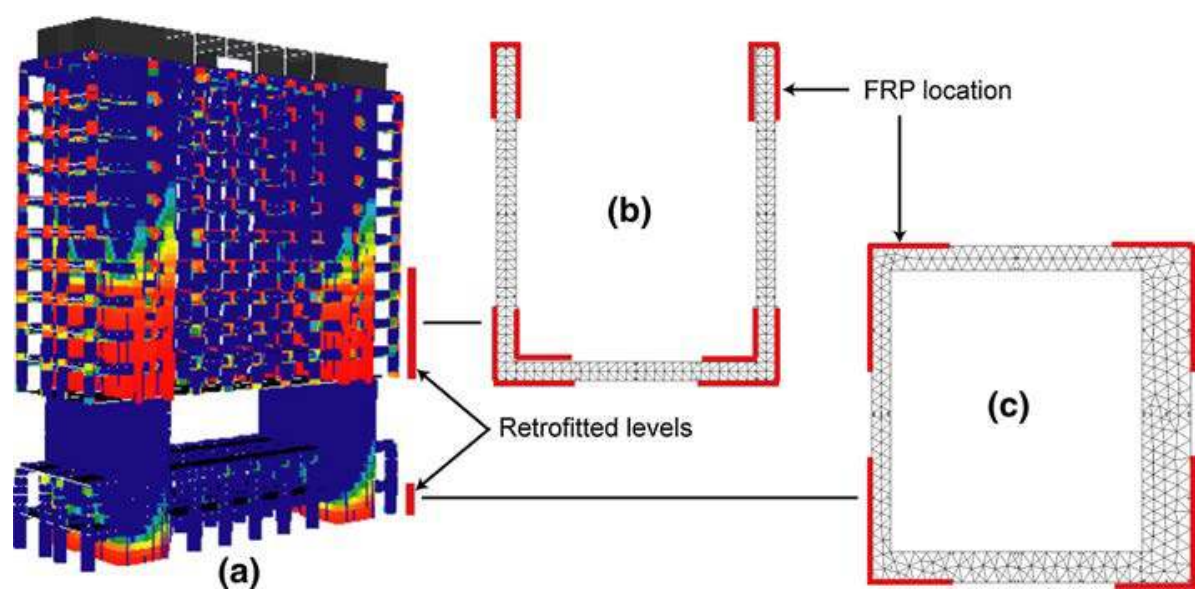

Fig. 16 GCH (FRP design no. 1)_Location of FRP sheets: a in the structure, $\mathbf{b}$ in a "U-type" pier and $\mathbf{c}$ in a "square-type" pier

at the two first levels above the deck and at the base of the building. No concrete failure due to compression or steel bucking is observed. According to Table 5, the damage level can be therefore identified as Moderate (level 2/5).

\section{Vulnerability assessment after FRP retrofitting}

A FRP retrofitting solution is studied hereafter with the objective, because of the particular importance of the $\mathrm{GCH}$, to decrease the damage expectance level from moderate $(2 / 5)$ to negligible (1/5) (Table 5; Fig. 15).

The nonlinear dynamic analysis presented in Sect. 3 highlights two critical areas in the structure: the base of the tower subject to maximal bending moments, and the first four floors above the deck where the geometry of the piers changes from "Rectangular-type" to "U-type". In these areas, concrete cracks (tension damage) and reinforcement bars yield. No important values of compression damage are observed and shear stresses are acceptable. The bending modes are mainly excited and torsional effects are negligible.

Following the previous remarks, the adopted design solution is to retrofit (numerically) the four main piers (P1 to P4, Fig. 2b) in order to increase their flexural capacity and to avoid steel bar yielding. This can be achieved by bonding FRP on both sides of the piers as FRP has a function similar to an external reinforcement. Other retrofitting solutions, such as columns confinement, are not studied hereafter as damage due to compression or shear is not significant.

\subsection{FRP design solution no. 1}

The chosen retrofitted areas are the four main piers at the underground level and at the four levels above the deck (Fig. 16). The FRP location takes into account the opening access in the piers. $5 \mathrm{~mm}$ thick sheets are introduced numerically on the four levels above the deck, and $4 \mathrm{~mm}$ thick sheets at the basement level. The thickness of the FRP sheets is calculated using the numerical interaction diagram (normal forces-bending moments) at the base of 


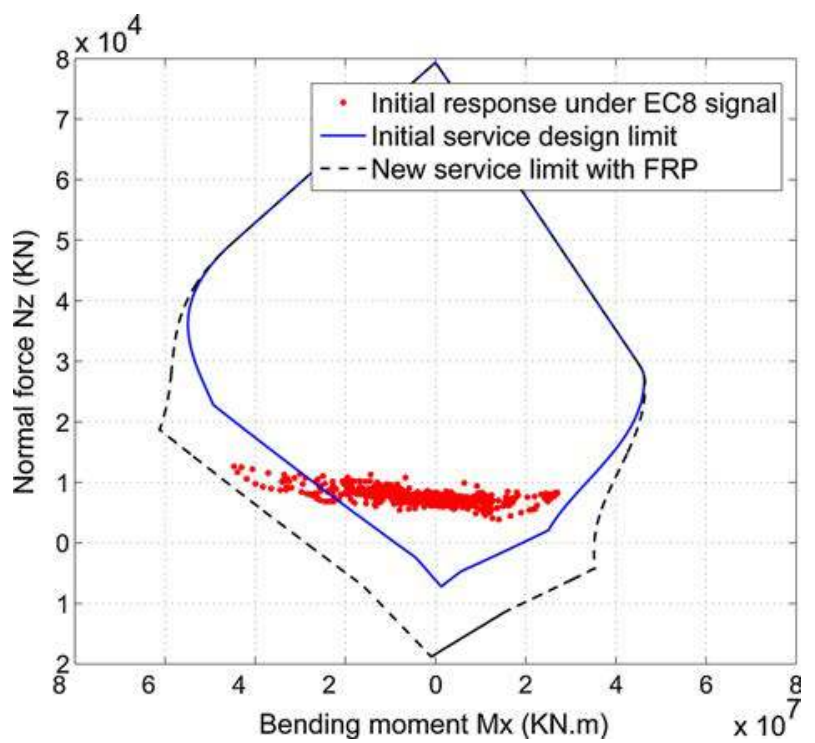

Fig. 17 GCH (FRP design no. 1)-Interaction diagram: normal force (Nz) versus flexural moment (Mx) at the base of a "U-type" pier (P4)

Table 6 GCH retrofitting-FRP properties

\begin{tabular}{llll}
\hline $\begin{array}{l}\text { Thickness of } \\
\text { the layers } t_{f} \\
\mathrm{~mm}\end{array}$ & $\begin{array}{l}\text { Ultimate } \\
\text { strength } f_{f u} \\
\mathrm{MPa}\end{array}$ & $\begin{array}{l}\text { Ultimate } \\
\text { strain } \varepsilon_{f u}\end{array}$ & $\begin{array}{l}\text { Young } \\
\text { modulus } \\
E_{f} \mathrm{GPa}\end{array}$ \\
\hline 1 & 1,400 & 0.0133 & 105 \\
\hline
\end{tabular}

the rectangular and "U" piers (Fig. 17) as follows: The results coming from the EC8 synthetic signal are compared to the "service design limit" corresponding to the steel yield threshold $(0.2 \%)$ and $60 \%$ of the concrete strength in compression (18 MPa). Adding FRP in the pier section allows defining a new "service design limit with FRP". The thickness is chosen such as all the numerical values are situated inside the new interaction diagram. Table 6 shows the retained FRP properties (typical values are used).

\subsubsection{Modeling strategy for FRP retrofitting}

In a finite element model based on multifiber beams, FRP can be simply introduced using additional fibers in the beam section (Fig. 18). Perfect bonding is assumed (no delamination) and a linear elastic brittle constitutive law is adopted for the additional fibers (Dufour 1998; LESSLOSS 2006; Desprez 2010). The comparison of the experimental results with the numerical ones for a monotonic loading proves the performance of the approach. It is important to notice however that this FRP modeling strategy is well adapted for flexural reinforcement but not for FRP column confinement. For this last case, a novel simplified modeling strategy and a new global constitutive law can be found in (Desprez et al. 2013). 


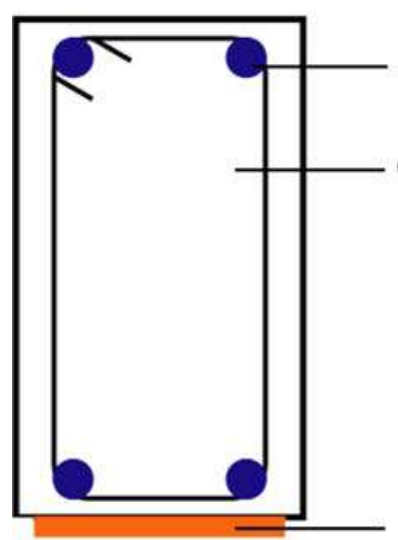

(a)

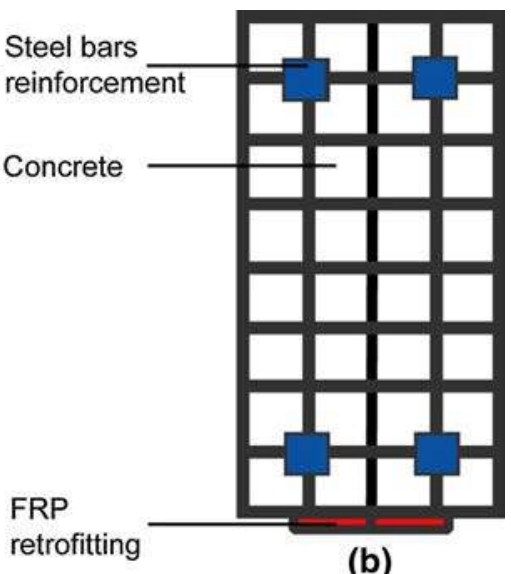

(b)

Fig. 18 Introducing additional FRP fibers in a multifiber beam section

\subsubsection{Nonlinear dynamic analysis of the retrofitted structure}

A modal analysis of the elastic retrofitted structure showed that the main natural frequencies remained unchanged. This is due to the small amount of the FRP sheets used. Nevertheless, as it is shown hereafter, the nonlinear response of the building is found extensively modified. More specifically, Fig. 19a, b shows that the floor displacements and inter-story drifts in the longitudinal direction (X) are higher for the retrofitted than for the non-retrofitted configuration. The transverse direction (Y) displacements and drifts remain almost unchanged. In both directions, the maximum values of curvatures are now shifted upper on the structure (Fig. 19c).

The concrete damage distribution $D_{1}$ (Fig. 20a) shows a more extended area of damage due to tension in comparison with the non-retrofitted structure (Fig. 14). Tensile cracks are significant at the base of the tower and above the deck and they reach the fifth level. Damage distribution due to compression is similar with the non-retrofitted case, with a small increase on the maximal value $\left(D_{2}=0.3\right)$.

The addition of FRP limits the strains and avoids the creation of plastic hinges inside the reinforced areas (Fig. 20b). However, new plastic zones appear just above the retrofitted elements. The discontinuity of the FRP sheets leads to new areas of strain location in the structure and thus to new sources of potential vulnerability. This clearly indicates the necessity of performing nonlinear dynamic analysis to choose the optimum retrofitting design solution.

A Fast Fourier Transform (FFT) of the top displacement time histories for the retrofitted and the non-retrofitted structures highlights a shift in frequencies that is less important when FRP is introduced (Fig. 21). The retrofitted structure is subject to more significant accelerations (Fig. 22) and to higher internal forces that result to increased maximum displacements values.

\subsubsection{Damage level assessment: FRP design solution no. 1}

At the final step of the calculation, the structure presents cracks at the base and on the first five levels above the deck. A moderate yielding of the steel bars $\left(\varepsilon_{\max }=2.617 \times 10^{-3}\right)$ appears above the retrofitting areas (Fig. 20b) while no concrete compression failure or 

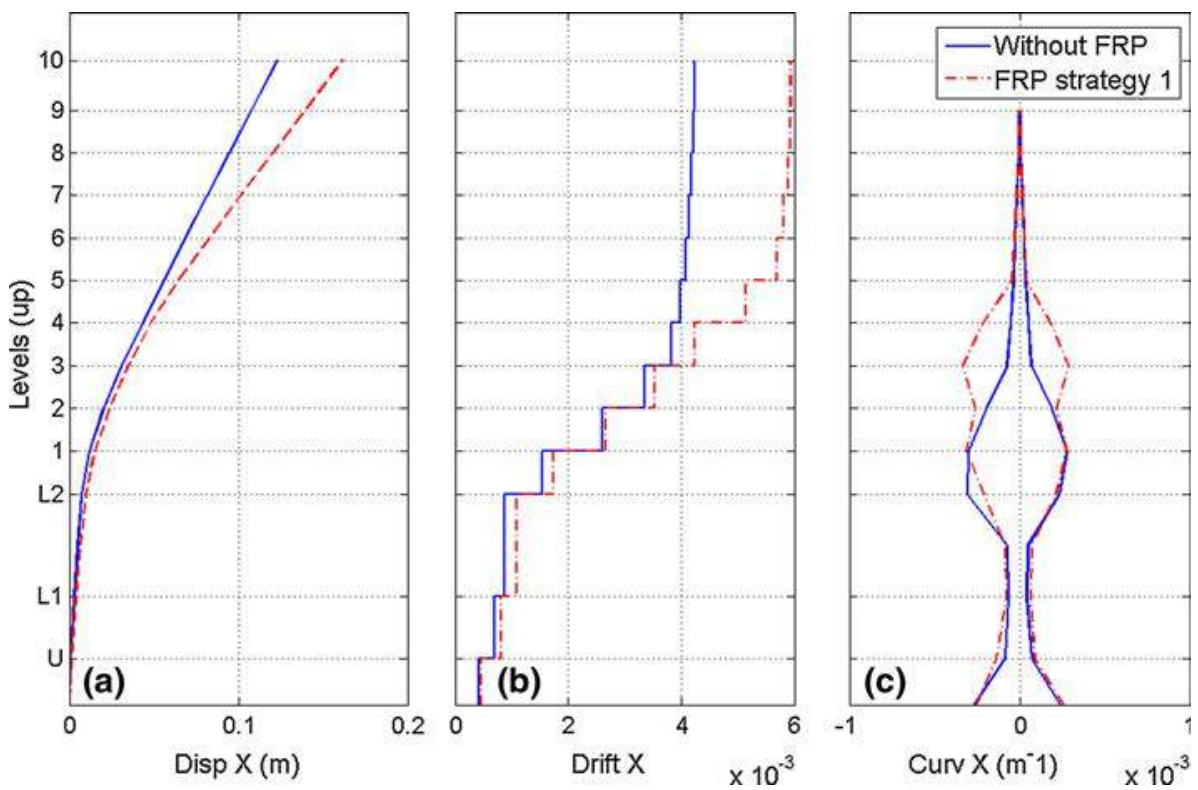

Fig. 19 GCH (FRP design no. 1)—retrofitted versus non-retrofitted configuration. Response of the pier P4 in the $\mathrm{X}$ direction: a displacements, $\mathbf{b}$ inter-story drifts, $\mathbf{c}$ curvatures

(a)

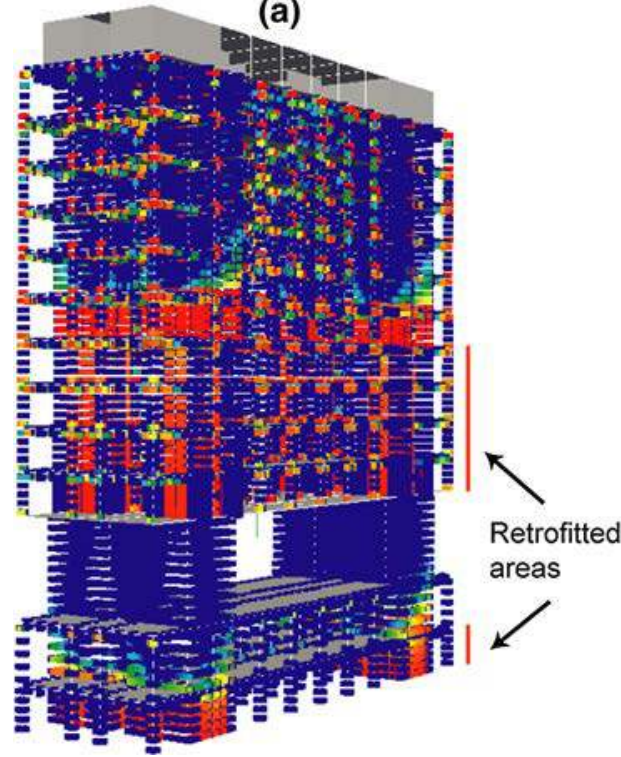

(b)

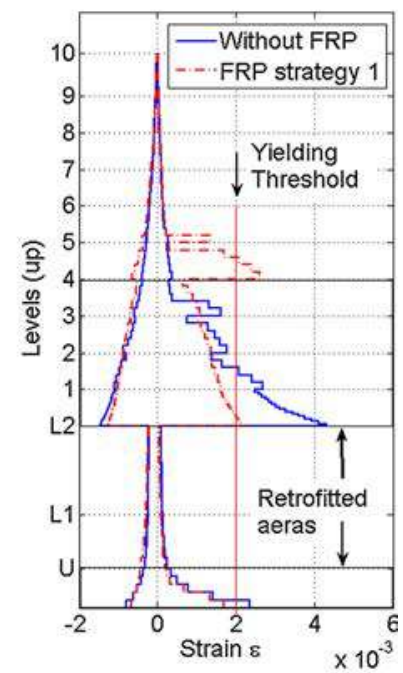

Fig. 20 GCH (FRP design no. 1) - a Distribution of $D_{1}$ (tension damage), final step and b envelop of strains in the steel bars of the pier P4 (yielding threshold at $0.2 \%$ )

steel bar buckling is observed. It is also important to notice that strains in FRP reinforcement are small and thus the risk of debonding, delamination or failure is limited. According to the classification presented in Table 5, the damage level is however 

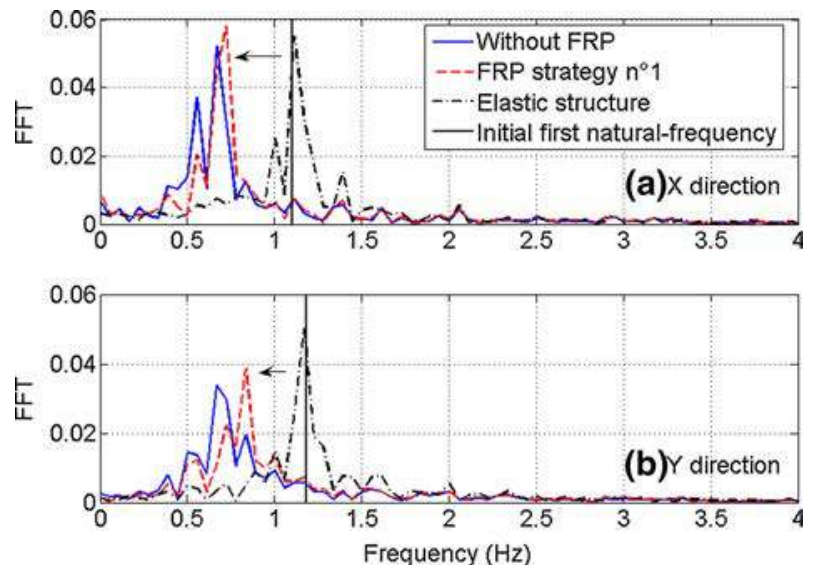

Fig. 21 GCH (FRP design no. 1) - FFT of the top displacement time histories — with and without FRP retrofitting Vs. elastic model: a longitudinal direction $\mathrm{X}$ and $\mathbf{b}$ transverse direction $\mathrm{Y}$

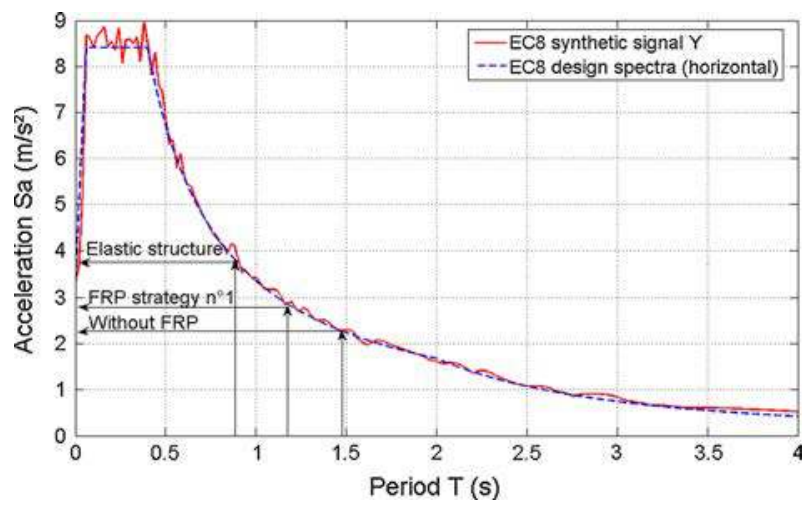

Fig. 22 GCH (FRP design no. 1) — spectral acceleration with Vs. without FRP retrofitting versus elastic model, transverse direction

again Moderate (level 2/5) and thus the main objective of the retrofitting strategy is not achieved.

In order to achieve this goal, two new optimized design solutions are studied in the following sections.

\subsection{Retrofitting design optimization}

\subsubsection{Damage level assessment: FRP design solution no. 2}

Figure 23 shows the nonlinear dynamic response of the structure in the $\mathrm{X}$ direction for the case of the second design solution, where FRP are placed till the fifth level above the deck. The maximal displacements and inter-stories remain similar to the results of the first retrofitting design solution while the strain localization zones are simply shifted at the end of the retrofitted area (Fig. 24; Table 7). The damage assessment level is still "Moderate" (level 2/5) using local indicators and the EMS98 scale. 

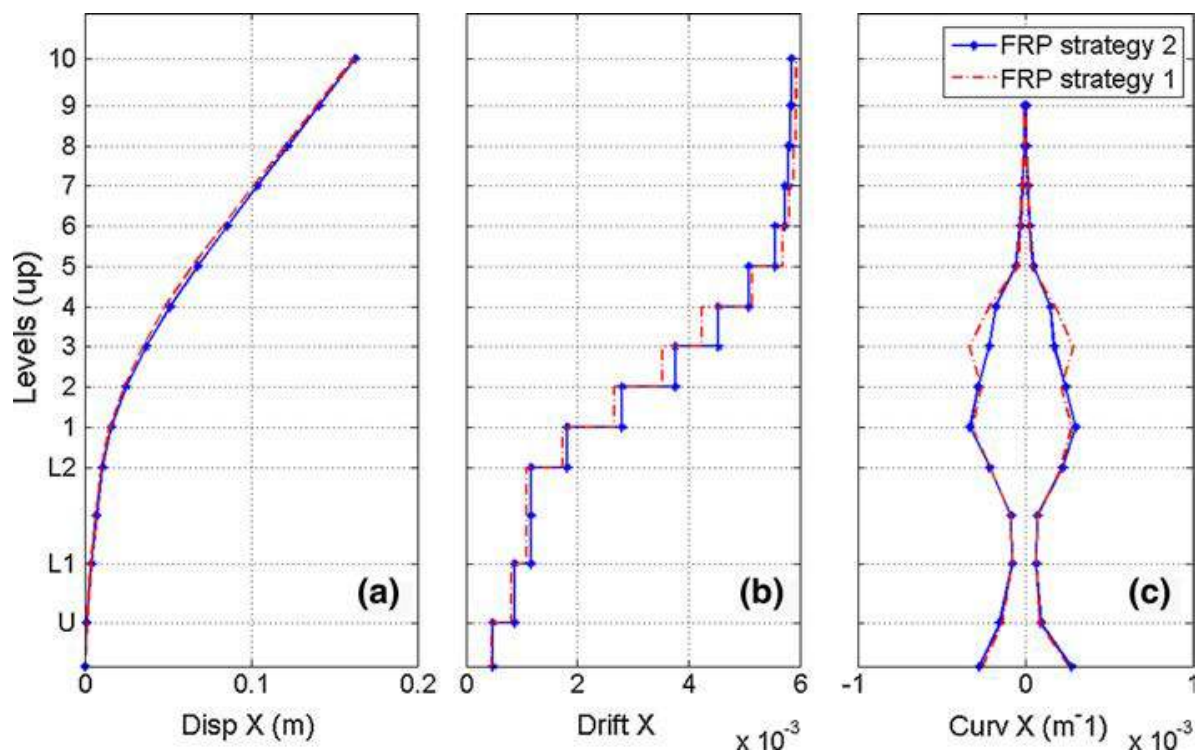

Fig. 23 GCH (FRP design no. 2)-FRP strategy no. 1 versus FRP strategy no. 2. Response of the pier P4 in the $\mathrm{X}$ direction: a displacements, $\mathbf{b}$ inter-story drifts, $\mathbf{c}$ curvatures

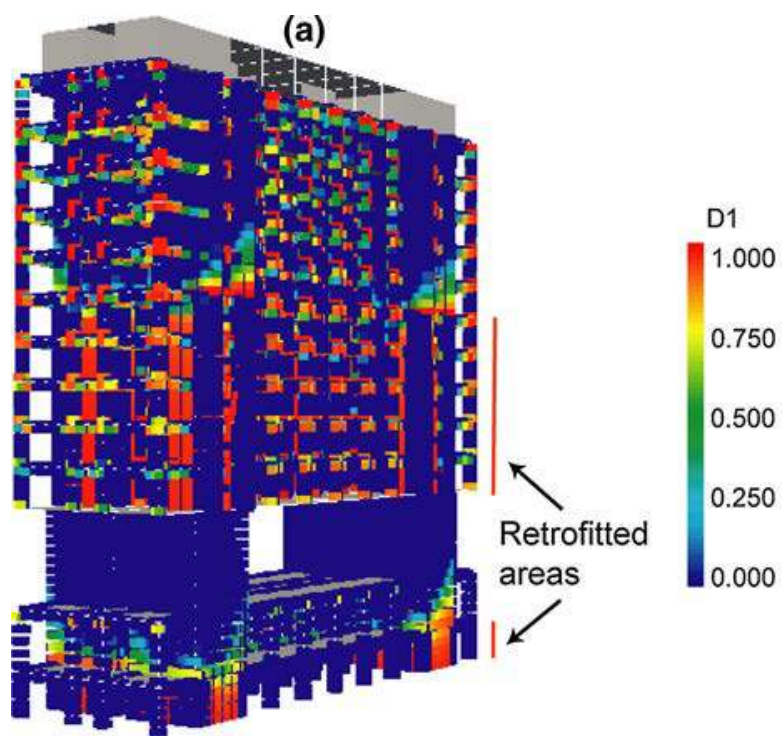

(b)

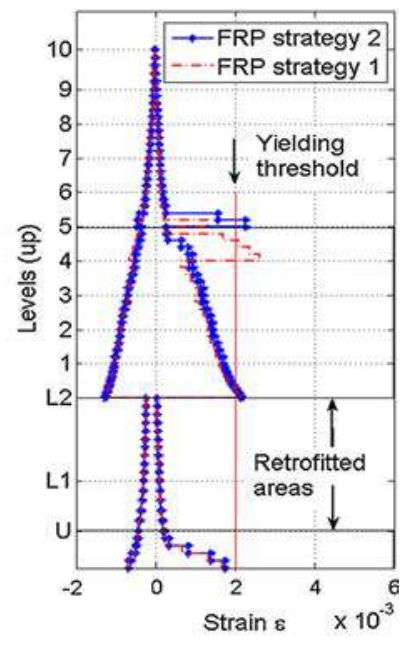

Fig. 24 GCH (FRP design no. 2)-a Distribution of $D_{1}$ (tension damage), final step and $\mathbf{b}$ envelop of strains in the steel bars of the pier P4; FRP strategy no. 1 versus FRP strategy no. 2

\subsubsection{Damage level assessment: FRP design solution no. 3}

From the previous results, it is obvious that the position of the plastic hinges is driven by the discontinuities between the retrofitted and the non-retrofitted areas. For the design solution no. 3, the FRP's thicknesses are adjusted considering the internal forces at each level. This leads to a progressive decrease of the FRP thickness of $0.5 \mathrm{~mm}$ at each level. Furthermore, 
Table 7 GCH-maximum responses in the pier P4 for the different FRP design solutions

\begin{tabular}{lllll}
\hline Indicator (Max) & Non-retrofitted structure & FRP design no. 1 & FRP design no. 2 & FRP design no. 3 \\
\hline Top disp X (m) & $132.3 \times 10^{-3}$ & $161.6 \times 10^{-3}$ & $162.6 \times 10^{-3}$ & $163.5 \times 10^{-3}$ \\
Top disp Y (m) & $127.0 \times 10^{-3}$ & $116.3 \times 10^{-3}$ & $116.0 \times 10^{-3}$ & $115.6 \times 10^{-3}$ \\
Drift X & $4.244 \times 10^{-3}$ & $5.937 \times 10^{-3}$ & $5.850 \times 10^{-3}$ & $5.853 \times 10^{-3}$ \\
Drift Y & $4.500 \times 10^{-3}$ & $4.438 \times 10^{-3}$ & $4.402 \times 10^{-3}$ & $4.400 \times 10^{-3}$ \\
Steel strains & $4.299 \times 10^{-3}$ & $2.617 \times 10^{-3}$ & $2.279 \times 10^{-3}$ & $2.050 \times 10^{-3}$ \\
D1 & 1 & 1 & 1 & 1 \\
D2 & 0.25 & 0.3 & 0.3 & 0.3 \\
Damage level & Moderate & Moderate & Moderate & Slight \\
$\quad$ local indicators) & & & & \\
\hline
\end{tabular}
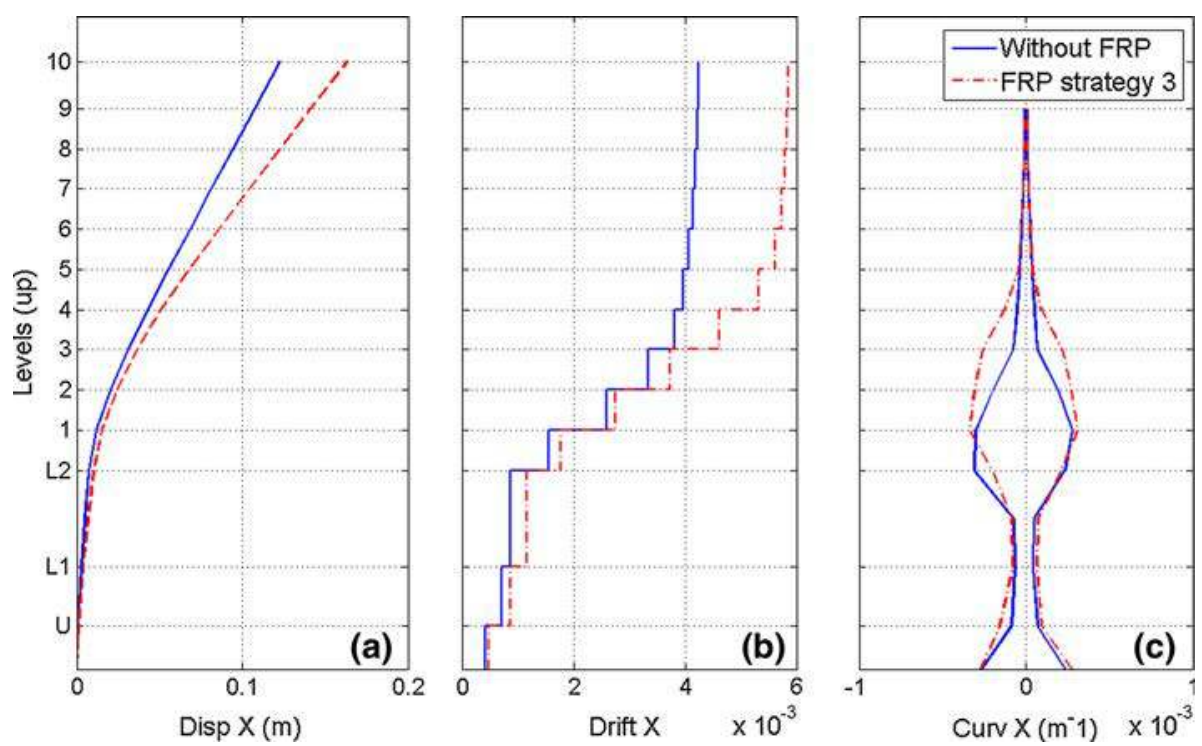

Fig. 25 GCH (FRP design no. 3) —optimized retrofitting versus non-retrofitted configuration. Response of the pier P4 in the X direction: a displacements, $\mathbf{b}$ inter-story drifts, $\mathbf{c}$ steel strains $\mathbf{d}$ curvatures

an additional level (6th) is retrofitted to reduce the influence of the discontinuities. For this design solution, FRP sheets have a $6 \mathrm{~mm}$ thickness at the first level and $3.5 \mathrm{~mm}$ thickness at the sixth level. The design of the FRP sheets at the basement is kept unchanged.

The maximum top displacement and inter-story drift (respectively $163.5 \times 10^{-3} \mathrm{~m}$ and $5.853 \times 10^{-3}$ ) are similar to the FRP design solution no. 1 (Fig. 25a, b; Table 7). Nevertheless, the progressive development of the curvature in the structure (Fig. 25c) limits the maximum strain values and cracks in concrete, allowing a more uniform energy dissipation (Fig. 26a); a smooth pattern of the strain localization zones is achieved (Fig. 26b). $D_{1}$ indicator is now distributed from the base of the building to the sixth level, no yielding of reinforced bars is observed and no cracks in concrete due to compression. The small $D_{2}$ increase comes from a better use of the compressed concrete part. According to the methodology of Table 5 the damage level in the EMS 98 scale is now considered "Negligible" (Level 1/5). 
(a)

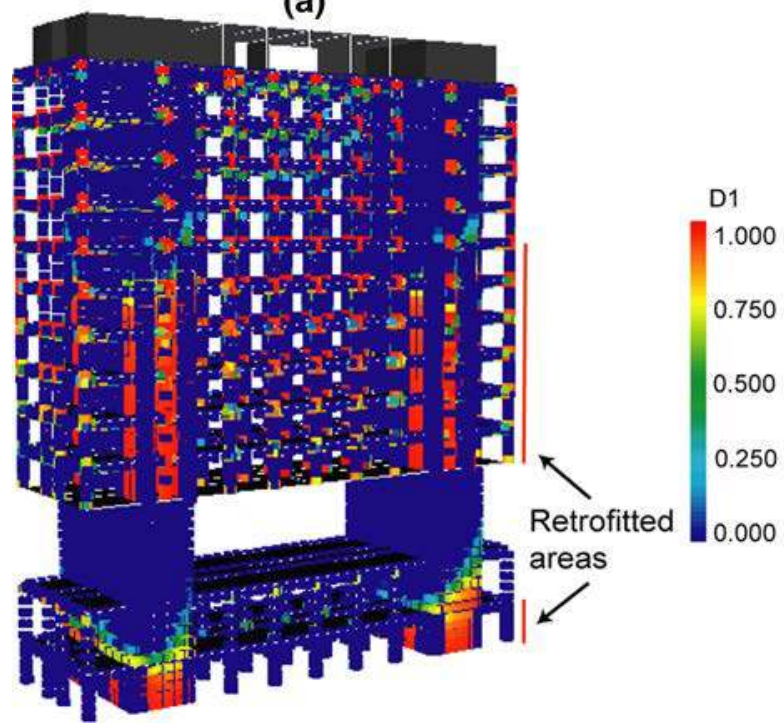

(b)

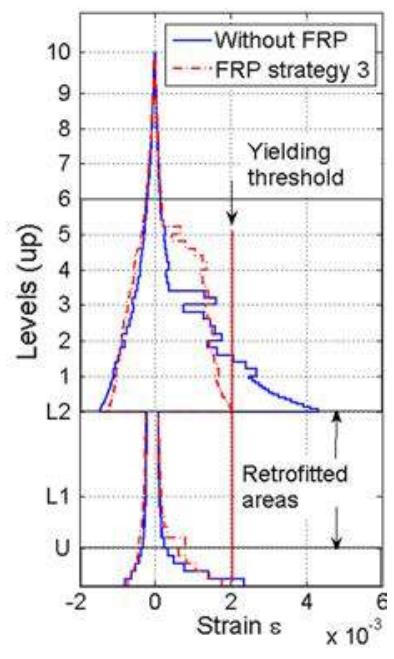

Fig. 26 GCH (FRP design no. 3). a Distribution of $D_{1}$ (tension damage), final step and b envelop of strains in the steel bars of the pier P4; Optimized retrofitting versus non-retrofitted configuration

Table 8 HAZUS

method-damage level for the Grenoble City Hall

\begin{tabular}{ll}
\hline HAZUS_damage levels & Maximum inter-stories drift \\
\hline Slight & $>1.5 \times 10^{-3}$ \\
Moderate & $>3.0 \times 10^{-3}$ \\
Important & $>8.0 \times 10^{-3}$ \\
Very important-Destruction & $>2.0 \times 10^{-2}$ \\
Building type : concrete shear & \\
$\quad$ wall $(\mathrm{C} 2)$-high $(\mathrm{H})$ & \\
\hline
\end{tabular}

\section{Local versus global indicators}

Table 7 presents an overview of the main characteristics of the structural response for all the different FRP design solutions. Top displacements and inter story-drifts (global variables) are found significantly increased in X direction whereas the damage level, based on the local state of materials, is found decreased.

In the following sections, the damage levels found using local indicators (Table 7) are compared to the damage levels from global indicators (HAZUS and Risk-UE).

\subsection{Damage assessment using HAZUS}

According to the HAZUS methodology (ATC-40 1996), the damage level of the building is defined from the maximum inter-story drift. Table 8 present the HAZUS damage levels for the $\mathrm{GCH}$, which is classified hereafter as a high level concrete building with shear walls.

Considering the initial GCH structure, without FRP, the maximum inter-story drifts in X and Y directions (Table 7) lead to a Moderate damage level (Table 8). After the first FRP 
Table 9 Risk-Ue method-damage level for the Grenoble City Hall

\begin{tabular}{|c|c|c|c|c|c|}
\hline \multirow[t]{2}{*}{ Damage level } & \multicolumn{5}{|c|}{ Maximum top head displacement $: \Delta(\mathrm{m})$} \\
\hline & $\begin{array}{l}\text { RISK-UE } \\
\text { (LM2)- } \\
\text { Threshold }\end{array}$ & $\begin{array}{l}\text { Non-retrofitted } \\
\text { structure }\end{array}$ & $\begin{array}{l}\text { FRP } \\
\text { design } \\
\text { no. } 1\end{array}$ & $\begin{array}{l}\text { FRP } \\
\text { design } \\
\text { no. } 2\end{array}$ & $\begin{array}{l}\text { FRP } \\
\text { design } \\
\text { no. } 3\end{array}$ \\
\hline Slight & $\Delta>0.7 \Delta_{\mathrm{y}}$ & $>26 \times 10^{-3}$ & $>26 \times 10^{-3}$ & - & $>26 \times 10^{-3}$ \\
\hline Moderate & $\Delta>0.7 \Delta_{\mathrm{y}}+0.05 \Delta_{\text {uy }}$ & $>40 \times 10^{-3}$ & $>61 \times 10^{-3}$ & - & $>90 \times 10^{-3}$ \\
\hline Important & $\Delta>0.7 \Delta_{\mathrm{y}}+0.2 \Delta_{\mathrm{uy}}$ & $>81 \times 10^{-3}$ & $>165 \times 10^{-3}$ & - & $>282 \times 10^{-3}$ \\
\hline $\begin{array}{l}\text { Very } \\
\text { Important }\end{array}$ & $\Delta>0.7 \Delta_{\mathrm{y}}+0.5 \Delta_{\mathrm{uy}}$ & $>163 \times 10^{-3}$ & $>373 \times 10^{-3}$ & - & $>666 \times 10^{-3}$ \\
\hline Destruction & $\Delta>0.7 \Delta_{\mathrm{y}}+\Delta_{\mathrm{uy}}$ & $>300 \times 10^{-3}$ & $>719 \times 10^{-3}$ & - & $>1,305 \times 10^{-3}$ \\
\hline \multicolumn{6}{|c|}{ With $\Delta_{\mathrm{uy}}=0.9 \Delta_{\mathrm{u}}-0.7 \Delta_{\mathrm{y}} ; \mathrm{U}=$ ultime; y=yield } \\
\hline
\end{tabular}

Table 10 GCH—damage level comparison—local approach, HAZUS approach and Risk-UE approach

\begin{tabular}{|c|c|c|c|c|}
\hline Damage assessment & $\begin{array}{l}\text { Non-retrofitted } \\
\text { structure }\end{array}$ & FRP design no. 1 & FRP design no. 2 & FRP design no. 3 \\
\hline \multicolumn{5}{|l|}{ Local method } \\
\hline Damage Level & Moderate & Moderate & Moderate & Slight \\
\hline Trend (1) & & Decreasing & Decreasing & Decreasing \\
\hline \multicolumn{5}{|l|}{ HAZUS method } \\
\hline Damage level & Moderate & Moderate & Moderate & Moderate \\
\hline $\begin{array}{l}\text { Damage indicator } \\
\text { location (2) }\end{array}$ & $30 \%$ & $58 \%$ & $57 \%$ & $57 \%$ \\
\hline Trend (1) & & Increasing & Almost unchanged & Unchanged \\
\hline \multicolumn{5}{|l|}{ Risk-UE method } \\
\hline Damage level & Important & Moderate & - & Moderate \\
\hline $\begin{array}{l}\text { Damage indicator } \\
\text { location (2) }\end{array}$ & $63 \%$ & $97 \%$ & - & $38 \%$ \\
\hline Trend (1) & - & Decreasing & - & Decreasing \\
\hline
\end{tabular}

(1) Trend evolution of damage indicators from the previous tested case

(2) Damage indicator location considering for example the HAZUS method and the first FRP design case, the maximal drift is $5.937 \times 10^{-3}$ (Table 7), leading to a Moderate damage level (Tables 8 ). The lower and upper thresholds are respectively $3.0 \times 10^{-3}$ and $8.0 \times 10^{-3}$. Considering the lower threshold as $0 \%$ and the upper one as $100 \%$ of the possible progression in the considered damage level, the $5.937 \times 10^{-3}$ value is thus situated at $58 \%$

strengthening, inter-story drifts are increased in the $\mathrm{X}$ direction, and are almost unchanged in the Y direction. According to the HAZUS assessment, the damage level remains Moderate. The same conclusions are drown for the second and third retrofitting configurations. Considering the local approach however, results are different for the 3rd retrofitting scheme, where the damage level is classified as Slight (Table 10). Furthermore using the HAZUS approach, the retrofitted configurations lead to an increase of the maximal inter-story drift and thus we get closer to the upper damage threshold. This trend is opposite to the results obtained with the local approach, where damage decreases with FRP retrofitting (Table 10). This contradiction on the damage assessment based on the HAZUS and the local methods can lead to significant errors. 


\subsection{Damage assessment using Risk-UE}

To apply the Risk-UE LM2 (RISK 2003) methodology, pushover analyses are needed. The damage levels thresholds depend then on the top displacement at "elastic" and "ultimate" limits of the building (Table 9). The static target displacement is then commonly used to define the reached damage level. However, having a deeper knowledge of the structure motion, the damage level is here defined from the maximal top displacement of the structure during dynamic analyses. In this study, the damage thresholds have been defined using pushover analysis on the GCH detailed in (Desprez 2010), available for the initial structure and the FRP designs 1 and 3.

Considering the initial GCH structure, without FRP, the maximum top displacement in X and Y directions (Table 7) lead to an Important damage level (Table 9). After the first FRP strengthening, top displacements are increased in the $\mathrm{X}$ direction, and are slightly decreased in the Y direction. Due to the higher capacity of the building however, the Risk-UE damage level thresholds are higher in the retrofitted configuration and the damage level becomes Moderate. The same conclusions are drown for the second and third retrofitting configurations. The Risk-UE damage indicator trend for the studied configurations is in accordance with the results of the local analysis: with better retrofitting design, the damage index decreases (Tables 7 and 10). However, considering the resulting classifications for the non-retrofitted and the 3rd retrofitting scheme results are not identical (Important vs. moderate, moderate vs. slight respectively, see Table 10). The use of global or local quantities can therefore lead to contradictory conclusions depending on the adopted assessment methodology.

\subsection{A new indicator for the damage state assessment}

Considering the local indicators as the accurate way for structure assessment, it is however still necessary to provide efficient global indicators. Indeed, in a post-seismic situation, global indicators can be used in concordance with in-situ monitoring; allowing to quickly evaluate the damage state of a structure. Global indicators are also the most practicable way for vulnerability assessment in a design context, as for the engineering field.

In this article, it is shown that the use of FRP leads to changes in the dynamic behavior of the structure without significantly impacting its geometry (the location of the plastic hinges and the values of the internal forces can change). The use of global indicators for the damage assessment, based on defined building typologies, can however lead to inaccurate diagnostics. It seems that a new building typology should be created regarding to the "FRP retrofitted RC building"; nevertheless, this would be very difficult as there is no unique retrofitting configuration. Another solution could be to define a new global indicator bridging the gap between local and global fields. The curvature could play a part of this role as it is directly linked with the local strains (Figs. 19, 20, 25).

\section{Conclusions and perspectives}

This paper presents a simplified method to assess the vulnerability of a RC structure before and after FRP retrofitting:

- The structure is simulated using multifiber beam elements and uniaxial constitutive laws for concrete and steel taking into account the cyclic behavior of the materials.

- The comparison between ambient vibrations records and the numerical response shows the good performance of the model. 
- The structure is submitted to a synthetic signal in accordance with the Eurocode 8 requirements and the results of the nonlinear dynamic analysis are presented.

- Local indicators as concrete damage variables and steel strains are used to assess the damage level of the building following a methodology based on the EMS 98 and Lang (Lang 2002) research work.

- FRP retrofitting is added to the numerical model and optimized solutions are studied in order to decrease the vulnerability level of the structure.

The study highlights the advantages of a multifiber beam modeling strategy to perform 3D dynamic nonlinear numerical calculations with low computational demands. Comparison between several retrofitting design solutions shows that they can lead to different damage localization zones. The use of different methodologies for vulnerability assessment based on global (HAZUS, Risk-UE) or local (EMS 1998; Lang 2002) indicators can provide contradictory results. It is therefore necessary to develop concordant indicators. Future work should be focused on studying several earthquake levels and various structures in order to establish a good correlation between local and global damage indexes. Although local variables are most representative of the effective state of a structure, global indicators (top displacements and inter story-drifts) are easier to use. A simplified way to deal with this could be to adopt curvatures as complementary indicators. They can be determined from the first derivative of the inter-story drifts, or the second derivative of the displacements. For flexion dominated structural elements strains are directly linked to curvatures, something that allows bridging the gap between local and global variables.

Acknowledgments The authors are grateful for the financial support of the French ANR (National Agency for Research) program ARVISE (Analyse et Réduction de la vulnérabilité sismique du bâti existent), Projet ANR-2006-PGCU-007-01. The in-situ records and the synthetic signal used in the dynamics analysis were provided by Phillipe Gueguen and Clotaire Michel (Institut des Sciences de la Terre (ISTERRE), http://isterre. fr).

\section{References}

Antoniou S, Pinho R (2004) Advantages and limitations of adaptive and non-adaptive force-based pushover procedures. J Earthq Eng 8(4):497-522

ATC-40 (1996) Seismic evaluation and retrofit of concrete buildings. Applied Technology Council

Cast3m, Official website http://www-cast3m.cea.fr. Accessed 13 Dec 2013

Causse M, Cotton F, Cornou C, Bard P-Y (2008) Calibrating median and uncertainty estimates for a practical use of empirical Green's functions technique. Bull Seismol Soc Am 98(1):344-353

Chopra AK, Goel RK (2001) A modal pushover analysis procedure to estimate seismic demands for buildings: theory and preliminary evaluation. PEER Report, Pacific Earthquake Engineering Research Center

Chopra AK, Goel RK (2004) A modal pushover analysis procedure to estimate seismic demands for unsymmetric-plan buildings. Earthq Eng Struct Dyn 33:903-927. doi:10.1002/eqe.380

Combescure D (2000) Modélisation des structures de génie civil sous chargement sismique à l'aide de castem 2000. CEA, Direction de l'énergie nucléaire, département modélisation de systèmes et structures, service d'études mécaniques et thermiques, Rapport DM2S. http://www-cast3m.cea.fr/index.php? xml=complements. Accessed 13 Dec 2013

Desprez C (2010) Analyse et réduction de la vulnérabilité sismique des structures existantes: renforcement par collage de tissus de fibres de carbone (TFC). Ph.D., Institut National Polytechnique de Grenoble. http:// tel.archives-ouvertes.fr/tel-00560438. Accessed 13 Dec 2013

Desprez C, Mazars J, Kotronis P, Paultre P (2013) Damage model for FRP-confined concrete columns under cyclic loading. Eng Struct 48:519-531

Dufour F (1998) Modélisation du comportement dynamique d'une structure à murs porteurs en béton armé renforcé à l'aide de tissu à fibres de carbone. Master of Science, CEA Saclay, ENS Cachan

EMS-98 (1998) European macroseismic scale 1998, Conseil de l'Europe. Cahiers du centre européen de géodynamique et de séismologie, vol 19 
Fajfar P, Marusic D, Perus I (2005) Torsional effects in the pushover-based seismic analysis of buildings. J Earthq Eng 9(6):831-854

Grange S, Kotronis P, Mazars J (2009) Numerical modelling of the seismic behaviour of a 7-story building: NEES benchmark. Mater Struct 42(10):1433-1442

Grange S, Botrugno L, Kotronis P, Tamagnini C (2011) The effects of soil-structure interaction on a reinforced concrete viaduct'. Earthq Eng Struct Dyn 40(1):93-105

Guedes J, Pégon P, Pinto A (1994) A fibre Timoshenko beam element in CASTEM 2000. Special publication nr. i.94.31. Technical report, J.R.C., I-21020, Ispra, Italy

Kalkan E, Kunnath SK (2006) Adaptive modal combination procedure for nonlinear static analysis of building structures. J Struct Eng ASCE. 132(11):1721-1731

Kotronis P, Mazars J (2005) Simplified modelling strategies to simulate the dynamic behavior of R/C walls. J Earthq Eng 9(2):285-306

Kotronis P, Ragueneau F, Mazars J (2005) A simplified modelling strategy for R/C walls satisfying PS92 and EC8 design. Eng Struct 27(8):1197-1208

La Borderie C (1991) Phénomènes unilatéraux dans un matériau endommageable: Modélisation et application à l'analyse des structures en béton. Ph.D Thesis, Université Paris VI, Paris, France

La Borderie C, Mazars J, Pijaudier-Cabot G (1994) Damage mechanics model for reinforced concrete structures under cyclic loading. In: Gerstle W, Bazant ZP (eds) A.C.I., vol 134. pp 147-172

Lang K (2002) Seismic vulnérability of existing building. Ph.D. thesis, Swiss Federal Institute of Technology, Zurich

LESSLOSS (2006) Integration of knowledge on FRP retrofitted structures. Deliverable 49, Sub-Project 7 , Techniques and methods for vulnerability reduction, pp 33-42

Mazars J, Kotronis P, Ragueneau F, Casaux G (2006) Using multifiber beams to account for shear and torsion: applications to concrete structural elements. Comput Methods Appl Mech Eng 195(52):7264-7281

Mazars J, Fr Ragueneau, Casaux G, Colombo A, Kotronis P (2004) Numerical modelling for earthquake engineering: the case of lightly RC structural walls. Int J Numer Anal Methods Geomech 28(7-8):857-874

Menegotto M, Pinto P (1973) Method of analysis of cyclically loaded reinforced concrete plane frames including changes In: geometry and non-elastic behaviour of elements under combined normal force and bending. IABSE Symposium on resistance and ultimate deformability of structures acted on by well-defined repeated loads, final report, Lisbon

Michel C (2007) Vulnérabilité sismique de l'échelle du bâtiment à celle de la ville. Ph.D. thesis, Laboratoire de Geophysique Interne et Techtonophysique (LGIT), Université Joseph Fourier, Grenoble I. http://tel. archives-ouvertes.fr/tel-00191024. Accessed 13 Dec 2013

Michel C, Guéguen P, El Arem S, Mazars J, Kotronis P (2009) Full-scale dynamic response of an RC building under weak seismic motions using earthquake recordings, ambient vibrations and modeling. Earthq Eng Struct Dyn 39(4):419-441

Penelis GG, Kappos AJ (2002) 3D Pushover analysis: the issue of torsion. In: 12th European conference on earthquake engineering. Paper 015

Planseisme (2011) French seismic intensity areas. http://www.planseisme.fr/Zonage-sismique-de-la-France. html. Accessed 13 Dec 2013

RISK-UE (2003) An advance approache to earthquake risk scenarios with applications to different European towns 